\title{
حقوق وواجبات المرأة المتضمنة في كتاب الفقه (نظام المقررات) لطالبات الصف الأول
} الثانوي

\section{توفيق بن إبراهيم البديوي}

أستاذ المناهج وطرق تدريس العلوم الشرعية المشارك كلية التربية- جامعة الملك سعود- السعودية
يارا عبدالمجيد العبدالكريم

محاضرة بقسم المناهج و طرق التدريس كلية التربية- جامعة الملك سعود- السعودية yalabdulkareem@ksu.edu.sa 
حقوق وواجبات المرأة المتضمنة في كتاب الفقه (نظام المقررات) لطالبات الصف الأول الثانوي

\author{
يارا عبدالمجيد العبدالكريم \\ محاضرة بقسم المناهج و طرق التدريس- كلية التربية- جامعة الملك سعود- السعودية \\ yalabdulkareem@ksu.edu.sa
}

\title{
توفيق بن إبراهيم البديوي
}

أستاذ المناهج وطرق تدريس العلوم الشرعية المشارك- كلية التربية- جامعة الملك سعود- السعودية

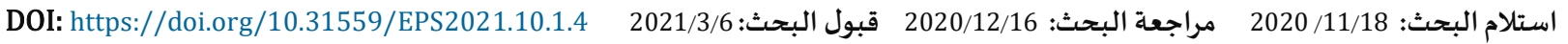

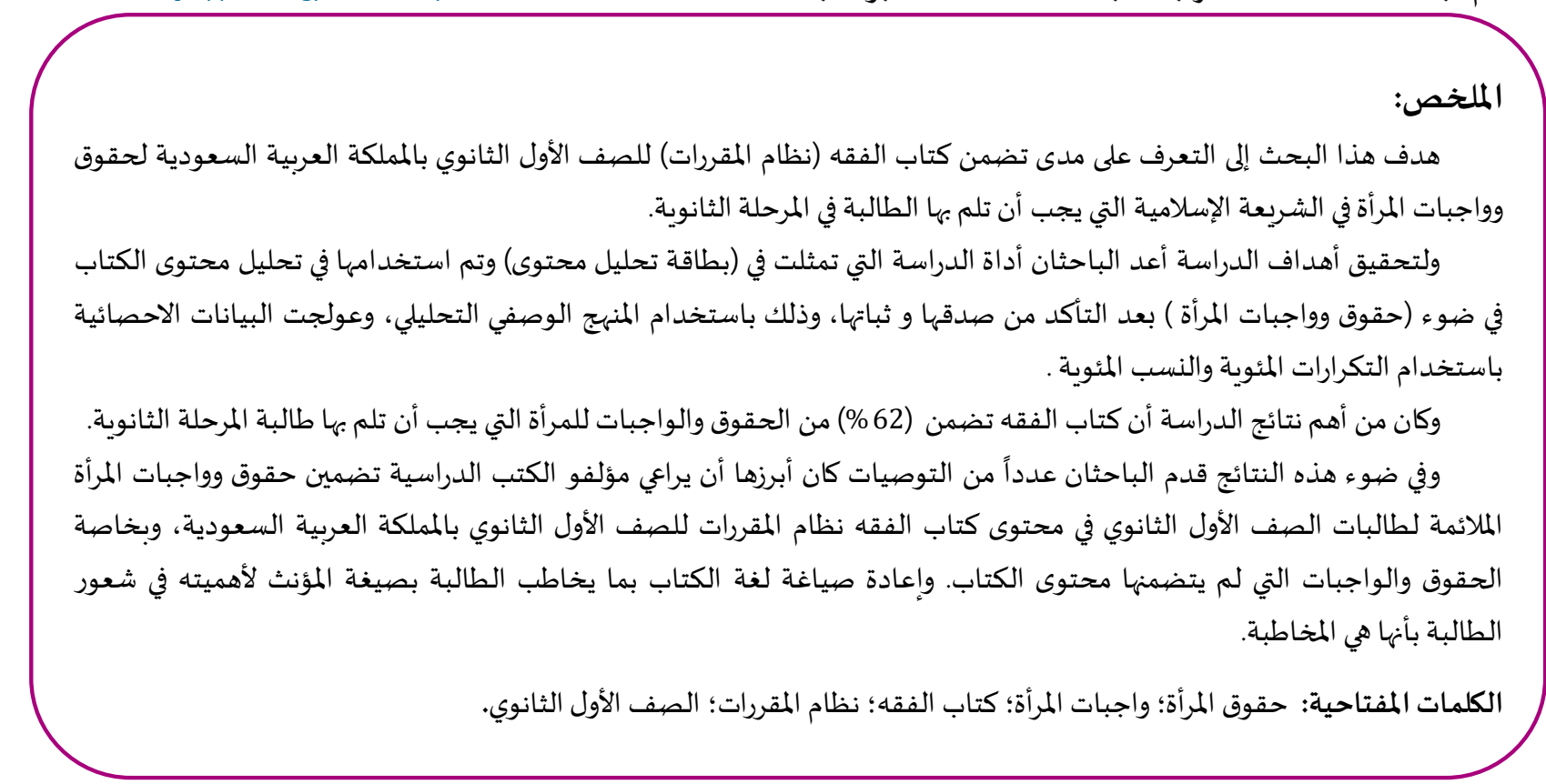

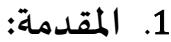

أنزل الله سبحانه وتعالى الشريعة الإسلامية للناس كافة؛ لتنظم حياتهم وعباداتهم وعلاقاتهم فيما بينهم. وإن المتأمل للواقع اليوم يرى أنه يشهد

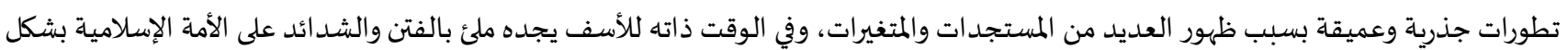

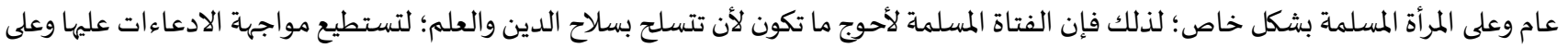

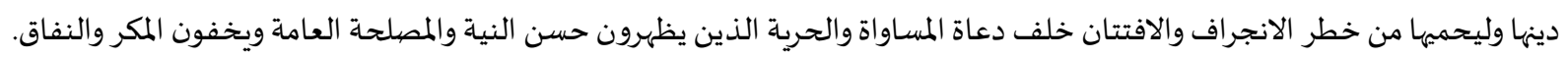
ولقد كرم الله جل وعلا المرأة ورفع شأهها وكرامتها ومكنها من حقوقها، كما شرع لها حقوقا تختلف عن غيرها وميزها في جوانب خاصاة بها بحكم

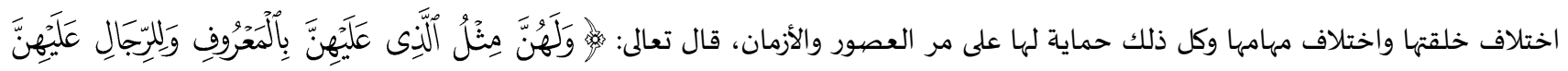

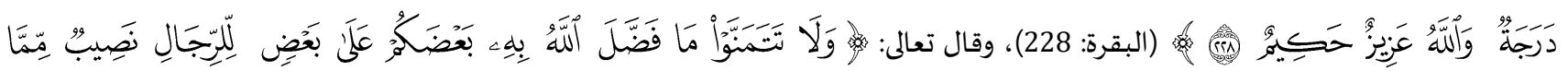




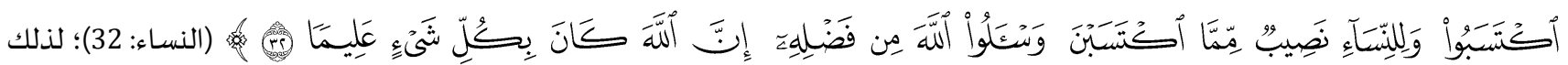

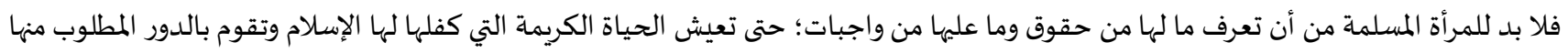

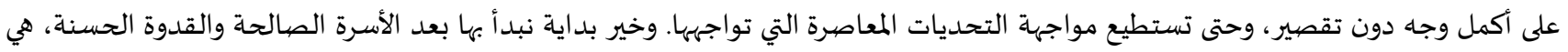

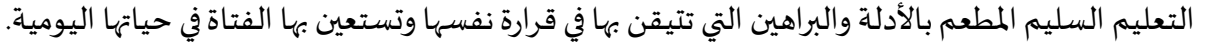

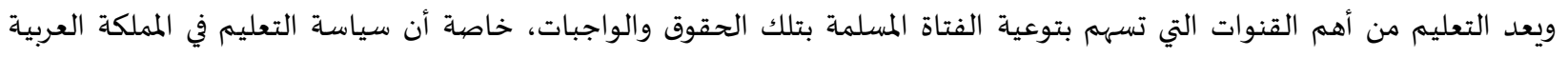
السعودية قد أقرت حق الفتاة في التعليم بما يلائم فطرتها ويعدها لمهمتها في الحياة على أن يتم هذا بحشمة ووقار في ضوء شريعة الإسلام. (وزارة المعارف،1970ه).

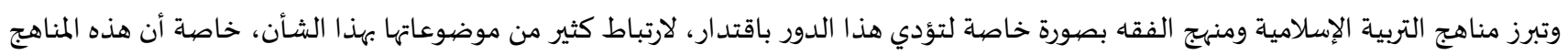

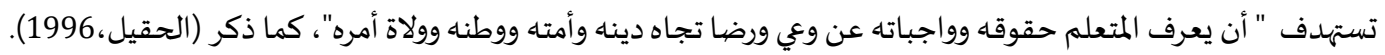

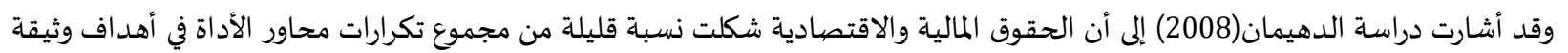

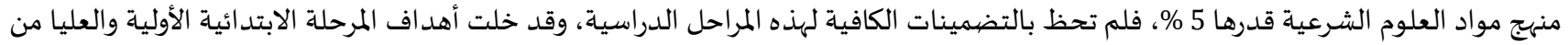

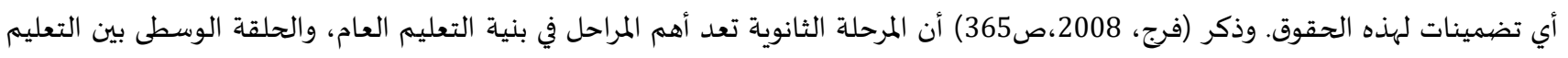

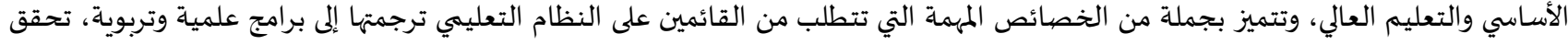

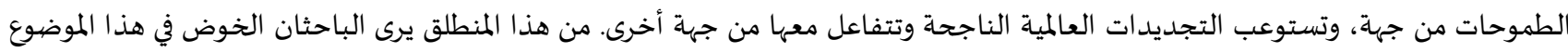

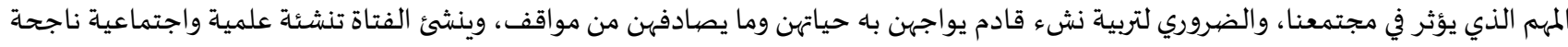

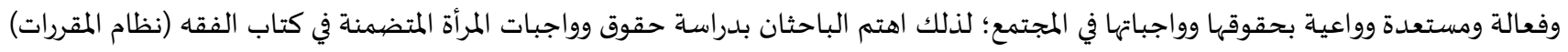
لطالبات الصف الأول الثانوي.

1.1.

زاد الاهتمام بحقوق المرأة في الآونة الأخيرة لما له من أهمية عالمياة، فيثير الإعلام الغربي قضايا تحرير المرأة، ويحاول تشويه صورة المرأة المسلمة مما

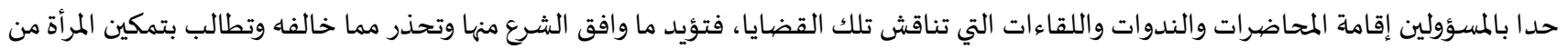

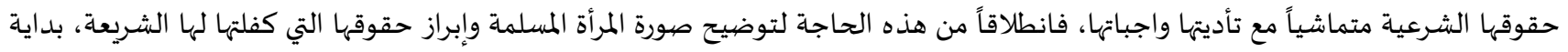

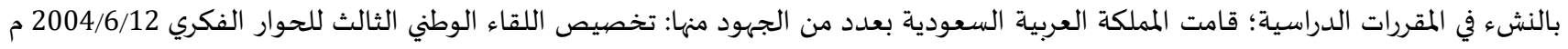

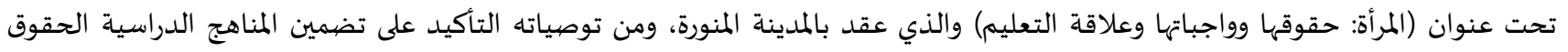

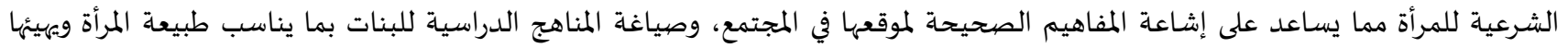

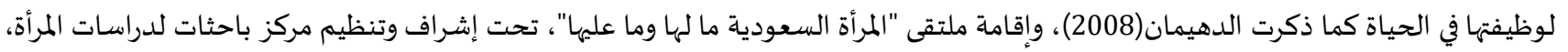

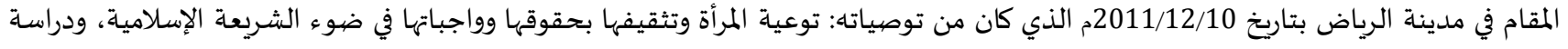

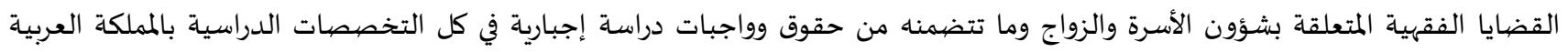

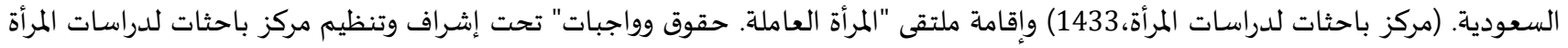

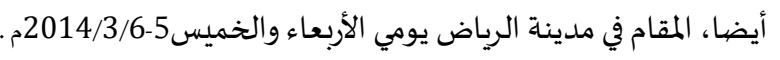

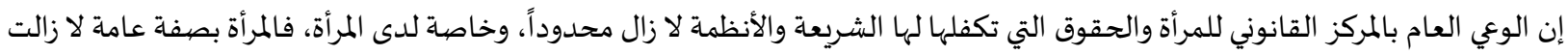

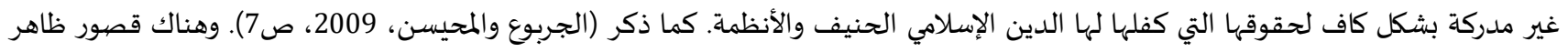

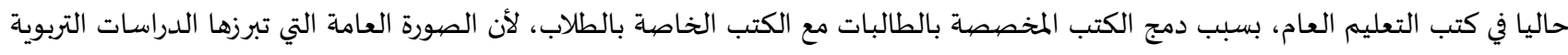

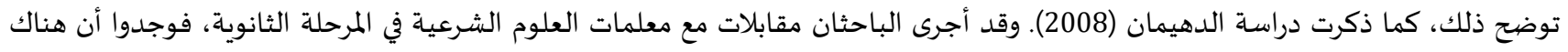

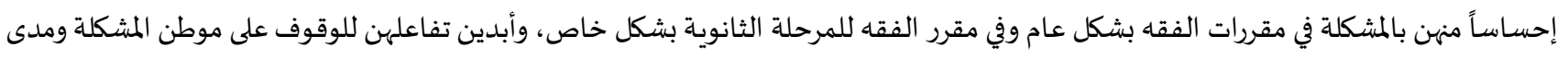

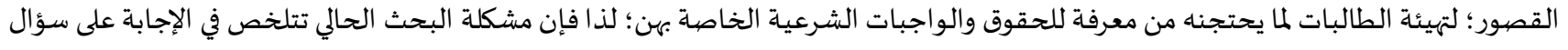

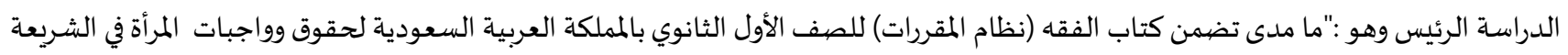
الإسلامية التي يجب أن تلم بها الطالبة في المرحلة الثانوية ؟

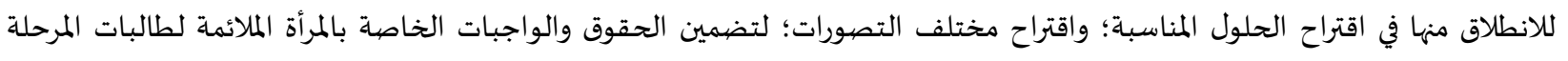
الثانوية، في كتاب مقرر الفقه (نظام المقررات) للصف الأول الثانوي. 
2.1 أسئلة الدراسة:

تطرح الدراسـة سؤالاً رئيساً: ما مدى تضيمن كتاب الفقه (نظام المقررات) للصف الأول الثانوي بالمملكة العربية السعودية لحقوق وواجبات

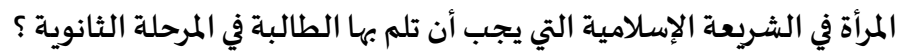
ويتفرع من هذا السؤال الرئيس الأسئلة الفرعية التالية:

• ما هي حقوق المرأة في الشريعة الإسلامية التي يجب أن تلم بها الطالبة من خلال مقرر الفقه نظام المقررات في المرحلة الثانوية؟

ما هي واجبات المرأة في الشريعة الإسلامية التي يجب أن تلم بها الطالبة من خلال مقرر الفقه نظام المقررات في المرحلة الثانوية؟

ما مدى توافر حقوق المرأة التي يجب أن تلم بها الطالبة في الصف الأول الثانوي، في كتاب الفقه (نظام المقررات) بالمملكة العربية السعودية؟

ما مدى توافر واجبات المرأة التي يجب أن تلم بها الطالبة في الصف الأول الثانوي، في كتاب الفقه (نظام المقررات) بالمملكة العربية السعودية؟؟

ما الآثار المترتبة على دمج كتب الفقه للبنين والبنات في المرحلة الثانوية في تضمنها للحقوق والواجبات التي يجب أن تلم بها الطالبة؟ ما التوصيات والمقترحات لتضمين حقوق وواجبات المرأة في الشريعة الإسلامية والتي يجب أن تلم بها الطالبة في كتب الفقه في المرحلة الثانوية

(نظام المقررات) (نمات

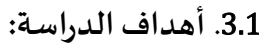

الهدف الرئيس من الدراسة هو: التعرف على مدى تضيمن كتاب الفقه (نظام المقررات) للصف الأول الثانوي بالمملكة العربية السعودية لحقوق وواجبات المرأة في الشريعة الإسلامية التي يجب أن تلم بها طالبة المرحلة الثانوية. ويتفرع منه الأهد اف التالية:

تحديد حقوق المرأة في الشريعة الإسلامية التي يجب أن تلم بها الطالبة من خلال مقرر الفقه نظام المقررات في المرحلة الثانوية.

تحديد واجبات المرأة في الشريعة الإسلامية التي يجب أن تلم بها الطالبة من خلال مقرر الفقه نظام المقررات في المرحلة الثانوية. التعرف على مدى تضمن كتاب الفقه (نظام المقررات) للصف الأول الثانوي بالمملكة العربية السعودية، حقوق المرأة التي يجب أن تلم بها الطالبة

في الصف الأول الثانوي.

التعرف على مدى تضمن كتاب الفقه (نظام المقررات) للصف الأول الثانوي بالمملكة العربية السعودية، واجبات المرأة التي يجب أن تلم بها الطالبة في الصف الأول الثانوي.

تحديد الآثار المترتبة على دمج كتب الفقه للبنين والبنات في المرحلة الثانوية في تضمنها للحقوق والواجبات التي يجب أن تلم بها الطالبة. تحديد التوصيات والمقترحات لتضمين حقوق وواجبات المرأة في الشريعة الإسلامية والتي يجب أن تلم بها الطالبة في كتب الفقه في المرحلة الثانوية (نظام المقررات) (ن)

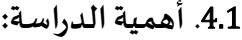

تثقيف الطالبات بالحقوق والواجبات الشرعية الخاصة بهن للوقوف في وجه الإعلام المنادي بتحرير المرأة ومساواتها بالرجل؛ لأن من حاجات

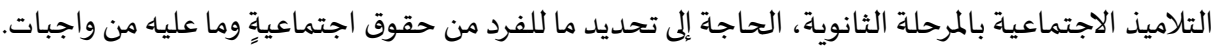
تقديم مؤشرات على مدى اهتمام مؤلفي كتب العلوم الشرعية بشكل عام وكتاب الفقه بشكل خاص بالحقوق والواجبات الشرعية الخاصة

تقديم تصورات ومقترحات لما ينبغي أن يتضمنه محتوى كتب الفقه للطالبات من حقوق شرعية وواجبات خاصة بالنساء. تفيد المختصين بتطوير كتب العلوم الشرعية.

التمهيد لبحوث أخرى تتعلق بتضمين حقوق وواجبات المرأة في مقررات العلوم الشرعية الأخرى سواء في المرحلة الثانوية أو المتوسطة أو الابتد ائية. (1) - 5.1 منهج الدراسـة: المنهج المستخدم في هذه الدراسة هو المنهج الوصفي التحليلي في تحديد الحقوق والواجبات الواجب توافرها في محتوى كتاب الفقه (نظام المقررات) للصف الأول الثانوي. 


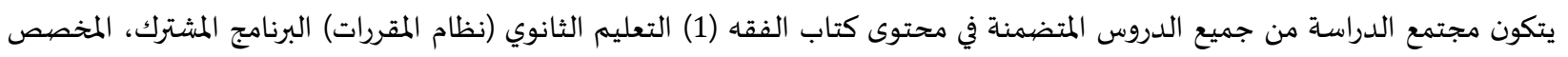
لطالبات الصف الأول الثانوي، والمعتمد من الوزارة في المملكة العربية السعودية للعام الدراسي (2010) والبالغ عدد صفيع هـاته 283 صفئحة. أما عينة

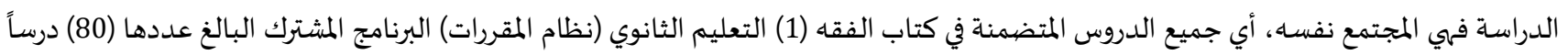

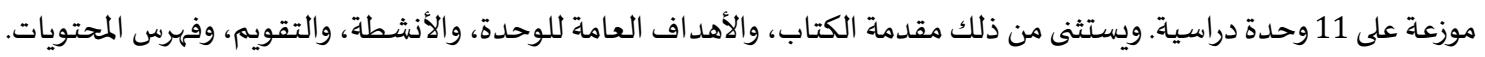

7.1.

بطاقة تحليل محتوى، تستخدم لتحليل محتوى كتاب الفقه للصف الأول الثانوي (نظام المقررات). واعتمد الباحثان في تصيميم البطاقة على

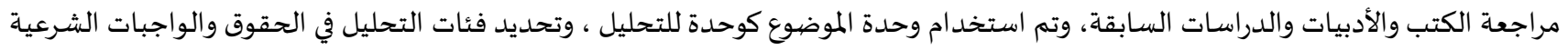

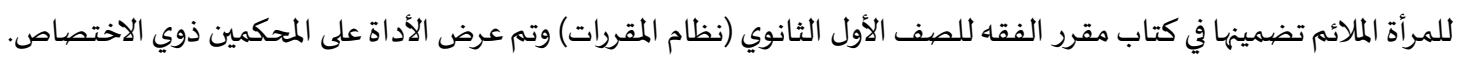

8.1 مصطلحات البحث:

(Hannallah \& Guirguis,1998) Rights : الحقدوق:

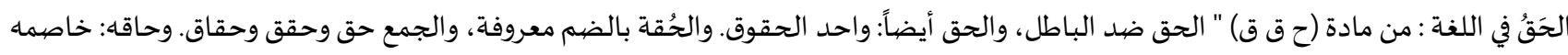

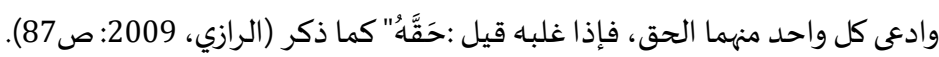

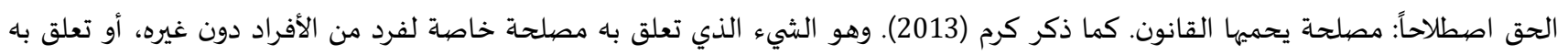

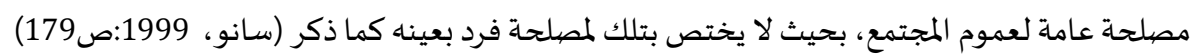

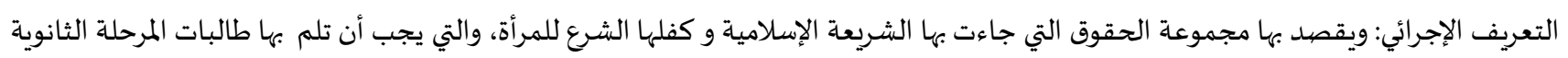
والواجب توافرها في كتاب الفقه (نظام المقررات).

الواجبات: Hannallah \& Guirguis,1998) Duties)

الواجب في اللغة: من مادة (و ج ب) وجب الشئ يجب وجوباً: لزم. واستوجباء: استحقه. ووجب البيع جِبَّة بالكسر. وأوجبت البيع فوجب. كما ذكر ( الرازي، 2009 :صأب الواجب اصطلاحاً: سلوك معين يلتزم باه شخص معين .كما ذكر (كرم، 2013) وهو ما طلب الشارع فعله على وجه اللزوم، بحيث يذم تاركاه ومع الذم

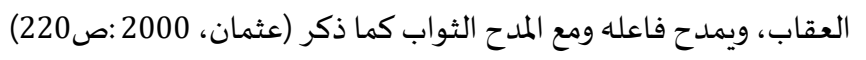

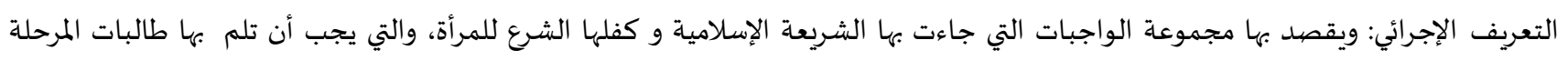
الثانوية والواجب توافرها في كتاب الفقه (نظام المقررات). كتاب الفقه:

هو كتاب الفقه (1) مقرر دراسي في العلوم الشرعية يقع ضمن الخطة الدراسية للمرحلة الثانوية لنظام المقررات، يدرس بواقع خمس ساعات أسبوعياً

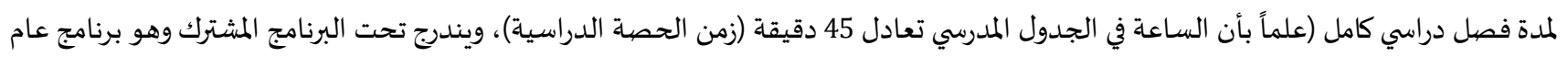

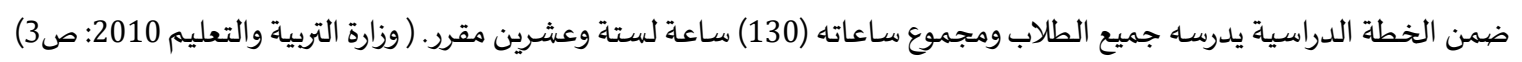

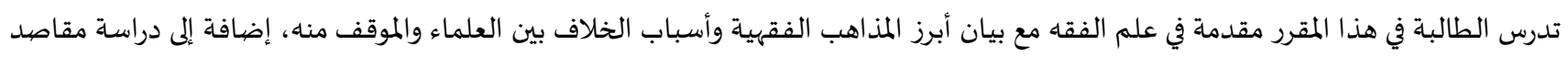

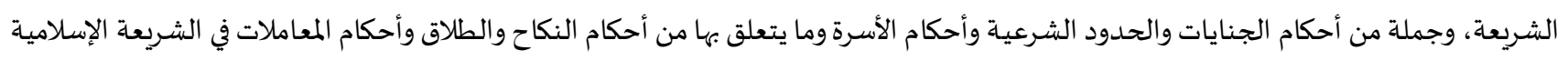

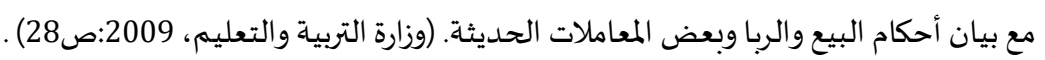
نظام المقررات:

هو هيكل جديد للتعليم الثانوي يتكون من برنامج مشترك يدرساه جميع الطلاب يتفرع إلى مسارين تخصصين أحدهما للعلوم الإنسانية والآخر للعلوم

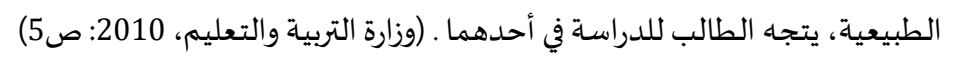

2. الإطار النظري والدراسـات السـابقة:

تستعرض الدراسة أربعة محاور هامة في الإطار النظري وهي : حقوق وواجبات المرأة، والفقه، والمرحلة الثانوية، ونظام المقررات.

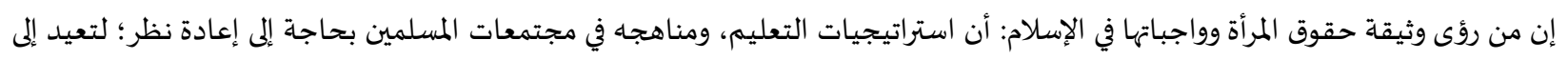

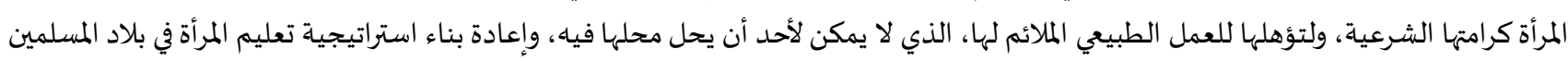


لتحقق الأهداف الأساسية وهي تخريج امرأة حسنة التعبد لربها، حسنة التبعل لزوجها، حسنة التربية لأبنائها، حسنة الإدارة لبيتها، حسنة الإعمار لمجتمعها فيما يخصها. وإن الخلل في تعليم المرأة المتمثل في تماثل منهجها التعليمي مع الرجل، بحيث يؤهلها للوظائف التي يؤهل لها الرجل؛ لأهما أعدا بطريقة واحدة، ونالا دراسة واحدة، هو اعتداء على حقها، وانتقاص لكرامتها، فلقد أثبتت الوقائع المعاصرة، علاقة هذا الخلل بالطلاق والإحباطات النفسية والمشكلات

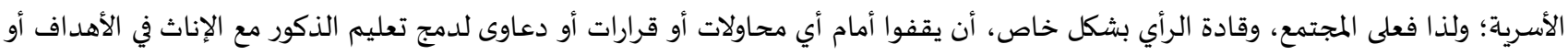

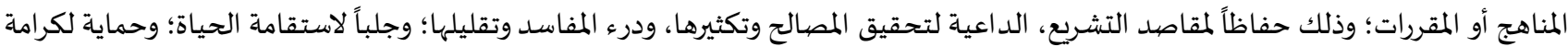

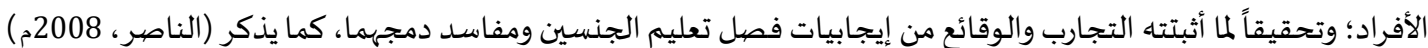

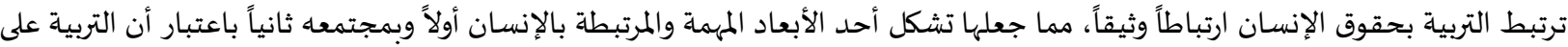

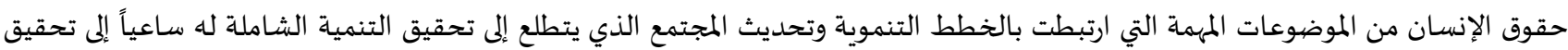
استقامة الحياة الاجتماعية وهذا كله لا يتم دون استحضار الحق في التعليم والنابع من أنه حق من حقوق الإنسان. كما أن تعليم حقوق الإنسان ليس

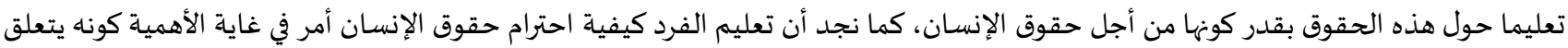

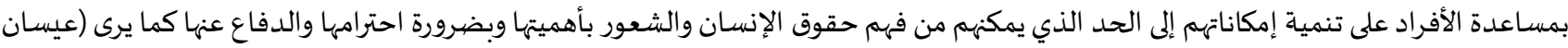

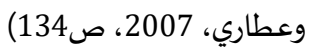

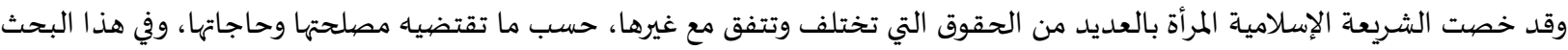
ذستعرض منها ما يلائم طالبات المرحلة الثانوية وقد تم تقسيم محاور حقوق المرأة إلى ثلاثة محاور هي محور الحقوق الشخصية مئه والاجتماعية والمالية

وعددها (29) حقاً.

إن الحقوق والواجبات تسهم في تحقيق مصلحة البشر، ودرء المفاسد عنهم ،لأنها من جملة أحكام الشريعة الإسلامية، وقد ساوت بين الرجل

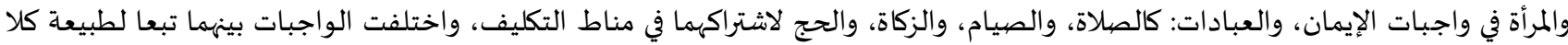

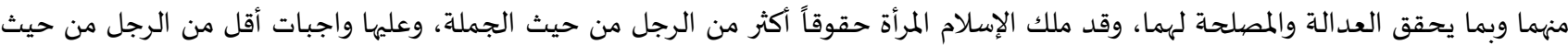
الجملة، وفي هذا البحث تم تقسيم محاور واجبات المرأة إلى ثلاثة محاور هي محور الواجبات الشخصية والاجتماعية والمالية وعددها لماتها (24) واجباً.

1.2. الدراسات السابقة: وقد تناولت بعض الدراسـات حقوق وواجبات المرأة مثل: دراسة الرويلي (2008) والتي كانت عبارة عن دراسة استطلاعية على عينة من طالبات جامعة الملك سعود في مدينة الرياض تناولت العوامل المؤثرة بوعي الشابة السعودية بحقوقها. وكذلك دراسـة الدهيمان (2008) والتي كانت عبارة عن دراسة تحليلية لأهد اف وثيقة منهج مواد العلوم الشرعية في التعليم الأساسي بالمملكة العربية السعودية في ضوء مراعاتها حقوق المرأة المسلمة. ودراسـة محمد (2013) التي بحث فيها عن إدراك الزوجة لحقوقها وواجباتها (في ضوء الكتاب والسنة) وعلاقته بجودة حياتها. وجاءت دراسات أخرى لتتناول حقوق الإنسان وتضيمينها في التعليم مثل:

دراسة التركي (2010) والتي بحث فهها عن مدى تضمين وثيقة منهج مواد العلوم الشرعية في التعليم الأساسي لمبادئ حقوق الإنسان. أما عن الفقه الإسلامي هو الصورة العملية للتصور الإسلامي، فالإنسان يوجد ضمن إطار اجتماعي وبيئي يتفاعل معاه بصور متعددة، وإذا كانت

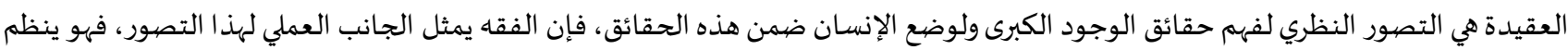
علاقة الإنسان مع الخالق عز وجل من خلال منظومة العبادات، وعلاقته بالآخرين ضمن قواعد وتشريعات وأنظمة يجمعها فقها المعاملات.

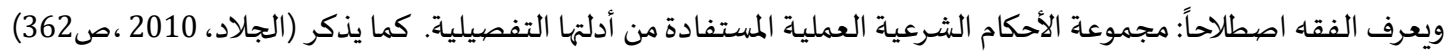

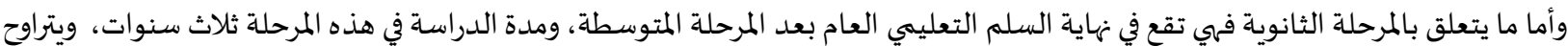

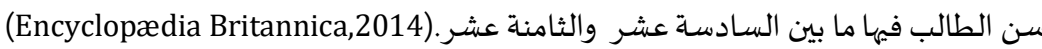
تناولت بعض الدراسـات تحليل المحتوى في العلوم الشرعية للمرحلة الثانوية في مجال جانب الفقه مثل: دراسة الخليوي (1994ه) التي كانت عبارة عن دراسة تقويمية لمحتوى منهج الفقه للصف الأول الثانوي للبنات بالمملكة العربية السعودية في ضوء المفاهيم الفقهية اللازمة. ودراسـة العتيبي (2004) التي بحث فيها تحليل محتوى كتاب الفقه للصف الثالث الثانوي في ضوء القضايا الفقهية المعاصرة. 
وفيما يخص نظام المقررات فهو هيكل جديد للتعليم الثانوي يتكون من برنامج مشترك يدرساه جميع الطلاب يتفرع إلى مسارين تخصصيين

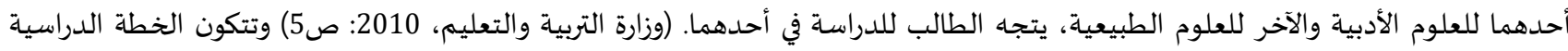

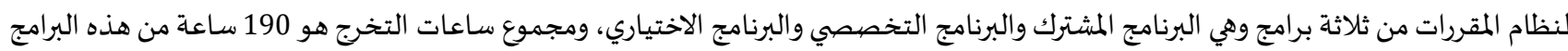
كالتالي: (المشترك 130 ساعة، التخصص المقررات من 55 ساعة، الاختياري 5 ساعات). يهدف نظام المقررات إلى تنمية شخصية المتعلم بشكل شمولي: معرفياً

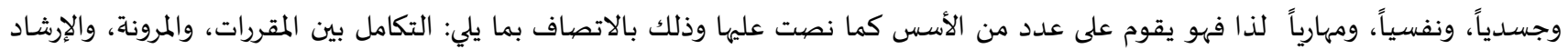

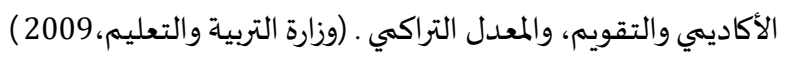
تناولت بعض الدراسـات نظام المقررات في المرحلة الثانوية مثل:

دراسة المحارب (2009) والتي بحث فيها مدى تحقيق نظام المقررات لأهداف المرحلة الثانوية من وجهة نظر المشرفين التربويين والمعلمين. ودراسـة العبدالكريم (2011) التي بحث فهها مدى تحقيق التعليم الثانوي بنظام المقررات في المملكة العربية السعودية لأهدافه من وجهة نظر الطلاب والطالبات. ودراسة الحسين (2013) التي تناول فيها المشكلات التدريسية التي تواجه معلمي المواد الاجتماعية في نظام المقررات الثانوي كما يراها المعلمون والمشرفون التربويون للمواد الاجتماعياة. واتفقت الدراسات السابقة مع الدراسة الحالية في كونها امتداد للدراسات التي اهتمت بحقوق المتونة المرأة في مجال التعليم، وكونها تناولت تحليل محتوى كتب العلوم الشرعية التعليمية في مجال جانب الفقه في المرحلة الثانوياة، أو تناولت دراسـة نظام المقررات في المرحلة الثانوية.

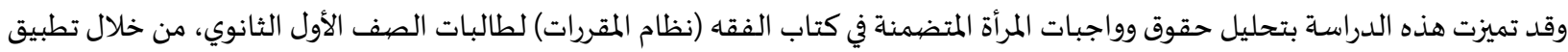
استبانة تحليل المحتوى، والاستفادة من الدراسات السابقة في منهجيتها البحثية ، والوقوف على أهم ما توصلت إليه من نتائج؛ وما قدمته من توصيات. 2.2

لتحقيق أهداف البحث والإجابة عن أسئلته اتبع الباحثان الخطوات الإجرائية التالية: إعداد الإطار النظري من خلال الاطلاع على المراجع والبحوث والدراسات السابقة التي اهتمت بتحليل كتب العلوم الشرعية بشكل عام بالإضافة

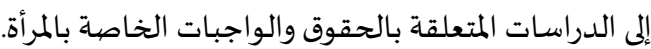
إعداد أداة البحث (بطاقة تحليل المحتوى) في صورتها الأولية واختيار محاورها وفئاتها، المتمثلة في قائمة بالحقوق والواجبات الخاصة بالمرأة الملائمة لطالبات المرحلة الثانوية. عرض الأداة على مجموعة من المحكمين للتحقق من صهدق الأداة، والذين يمثلون: 1. عينة من أساتذة وأستاذات قسم المناهج وطرق التدريس. 2. 3. عينة من معلمات التربية الإسلامية.

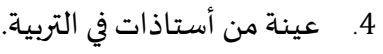
5. عينة من متخصصين في الشريعة والقانون، بهدف التعرف على آرائهم حول حقوق وواجبات المرأة الواجب توافرها في كتاب الفقه (نظام المقررات) لطالبات الصف الأول الثانوي. تعديل الأداة وفقاً لتوجيهات المحكمين، ثم صياغتها بصورة نهائية. إعد اد بطاقة تحليل المحتوى لرصد كل حق أو واجب توافر في مواضيع وحدات الكتاب، وقد تم بناء هذه البطاقة بناء على قائمة حقوق وواجبات المرأة التي تم إعدادها وعرضها على المحكمين في هذا البحث. تطبيق أداة البحث (بطاقة تحليل المحتوى) بشكلها النهائي على كتاب مقرر الفقه (نظام المقررات). جمع البيانات ومعالجتها إحصائياً. تحليل وتفسير نتائج البحث ومناقشتها. تقديم التوصيات والمقترحات في ضيوء ما أسفرت عنه نتائج هذا البحث. 3.2 - (الأسـاليب الإحصيائية: لمعالجة البيانات إحصائياً، استخدمت الباحثان الأساليب الإحصائية التالية:

$$
\text { التكرارات والنسب المئوية. }
$$


معادلة هولستي لقياس ثبات أداة التحليل.

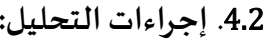

تمت عملية تحليل كتاب الفقه (1) التعليم الثانوي (نظام المقررات) وفقاً للإجراءات التالية: • ت تحديد وحدات التحليل:

تحددت وحدة التحليل في هذا البحث في وحدة الموضوع أو الفكرة الواردة في محتوى كتاب الفقه، والتي تمثل أهم وحدات تحليل المحتوى، كما

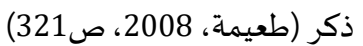
فكانت مواضيع الدروس في كتاب الفقه (1) التعليم الثانوي (نظام المقررات) هي وحدة التحليل، ويتكون الكتاب من 80 موضوعاً دراسياً. تحديد فئات التحليل:

تحددت فئات التحليل في هذا البحث في الحقوق والواجبات الخاصة بالمرأة والملائمة لطالبات المرحلة الثانوية الواردة بأداة التحليل وعددها (29) حقاً و (24) واجباً. ضو ابط التحليل: لقد التزم الباحثان في أثناء التحليل بالضيوابط التالية:

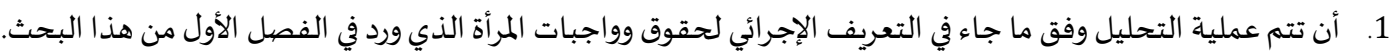

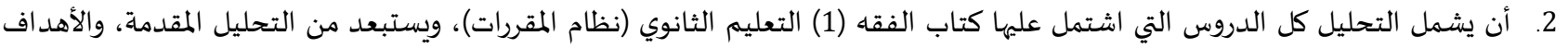
العامة للوحدة، وفهرس المحتويات. 3. تخصيص استمارة تحليل لتسجيل الحقوق و الواجبات التي وردت في كتاب الفقه (1) التعليم الثانوي (نظام المقررات)، وذلك لمراعاة الدقة وسلامة رصد نتائج التحليل. قواعد التحليل:

قام الباحثان عملية تحليل محتوى كتاب الفقه (1) التعليم الثانوي (نظام المقررات) وفق القواعد الآتية: 1. قراءة كل موضوع قراءة جيدة متأنية فاحصاة، بعد ترقيم مواضيع الدروس بشكل تسلسلي لتسهيل تحديد حقوق وواجبات المرأة التي تضمنها محتوى الكتاب. 2. استخراج حقوق وواجبات المرأة التي تضمنها كتاب الفقه، وفقاً للتعريف الإجرائي الذي ورد في الفصل الأول من هذا البحث باتخاذها تعريفاً لفئات التحليل. 3. تفريخ نتائج التحليل في جداول معدة لهذا الغرض، بإعطاء تكرار لكل حق او واجب عند ظهوره في موضيوع من مواضيع الدروس. خطوات التحليل: 1. اتخذ الباحثان موضوع الدرس الواحد في محتوى الكتاب وحدة للتحليل. 2. قراءة كل موضيوع بتأن ودقة، وتحديد الحق أو الواجب الذي تضونمناء. 3. تسجيل علامة تكرارية أمام كل حق أو واجب للمرأة توافر في الكتاب، عند نقطة تلاقيه مع رقم موضوعوع الدرس و ويتم تسجيل ذلك في بطاقة

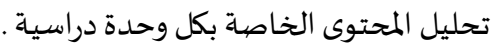

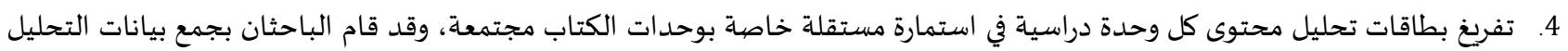
لمواضيع الكتاب الذي يتكون من ثمانين موضوعاً وإحدى عشر وحدة ببطاقة تفريغ واحدة: استمارة تفريغ البيانات، وذلك لتسهيل عملية جمع التكرارات واستخراج النسب المئوية. : ثبات التحليل:

للتحقق من ثبات التحليل في البحث الحالي قام أحد الباحثان بتحليل عينة عشوائية من مادة البحث نفسها مرتين وعلى فترتين متباعدتين: فحللا

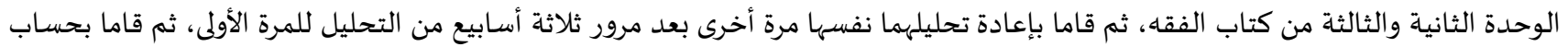

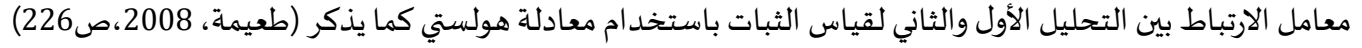

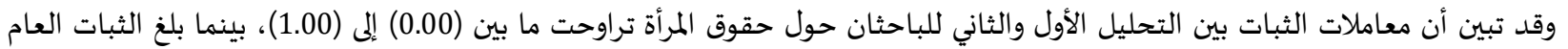
لنسب تكرارات حقوق المرأة (88 \%)، وهي ذسبة اتفاق عالية، مما يؤكد اتساق النتائج، ويطمئن إلى ثبات التحليل باعتبار أن هذا المعامل عال في مثل يل مذان

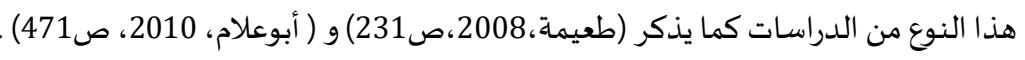


وتبين أن معاملات الثبات بين تحليل الباحثان الأول والثاني حول واجبات المرأة تراوحت ما بين (0.00) إلى (1.00) بينما بلغ الثبات العام لنسب

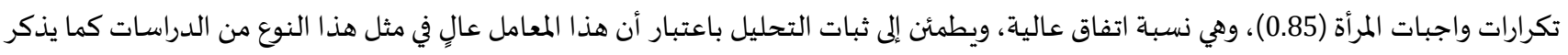

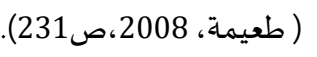
• • صددق التحليل

وقد قام الباحثان باختيار محللة أخرى للتحليل معهما لعينة عشوائية من مادة البحث؛ للتأكد من صداق التحليل واستعانا بإحدى أستاذات قسم المناهج وطرق التدريس الحاصلة على درجة الماجستير في طرق تدريس العلوم الشرعية (الاستاذة هدى الكثيري)؛ وذلك لتقوم بتحليل نفس المادة

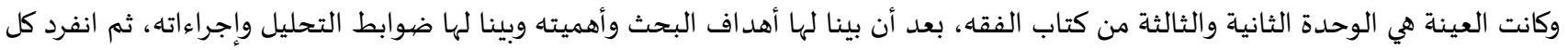

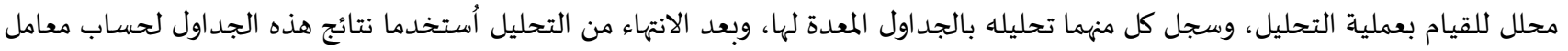

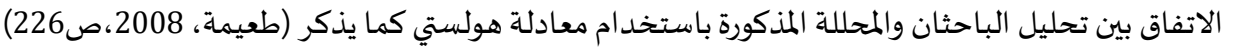

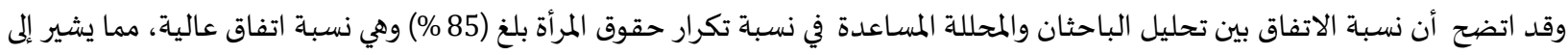

واتضح أن معاملات الثبات بين تحليل الباحثان وتحليل المحللة الأخرى تراوحت ما بين (0.00) إلى (1.00) بينما بلغ الثبات العام لنسبة تكرارات واجبات المرأة (86\%) ، وهي نسبة اتفاق عالية ، مما يشير إلى ثبات التحليل؛ ويسمح باستخدام أداة الدراسة في التحليل، والإجابة عن أسئلة الدراسة وصولا إلى تحقيق أهدافها.

3. 1.3. إجابة السؤال الأول للبحث: ما حقوق المرأة في الشريعة الإسلامية التي يجب أن تلم بها الطالبة من خلال مقرر الفقه نظام المقررات في المرحلة توصل الباحثان إلى الإجابة عن هذا السؤال من خلال الاطلاع على الكتب والمراجع والدراسات والمواقع الالكترونية التي تناولت مجال حقوق المرأة

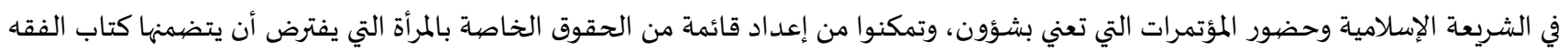

$$
\text { لطالبات الصف الأول الثانوي، في ضوء آراء مجمورعة الموتهرات من المحكمين. }
$$
جدول (1): قائمة ههائية بحقوق المرأة التي يفترض تضمينها في محتوى كتاب الفقه (نظام المقررات) للصف الأول الثانوي

\begin{tabular}{|c|c|c|}
\hline \multicolumn{2}{|c|}{ حقوق المرأة الملائمة لطالبات المرحلة الثانوية } & \multirow{2}{*}{ المحقور الشخصية } \\
\hline الرفق وحسن المعاملة من ولي أمرها & .1 & \\
\hline التعليم & .2 & \\
\hline العمل & .3 & \\
\hline الرعاية الصحية & .4 & \\
\hline حسن اختيار والدها & .5 & \\
\hline إثبات نسبها & 6 & \\
\hline حسن تسميتها & .7 & \\
\hline تربيتها التربية الصالحة & .8 & \\
\hline العدل بينها وبين إخوتها ذكورا وإناثا & .9 & \\
\hline 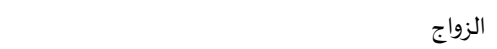 & .10 & \\
\hline استئذانها عند الزواج & .11 & \\
\hline المعاشرة بالمعروف للزوجة & .12 & \\
\hline 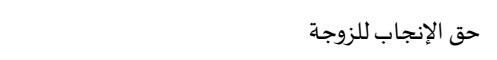 & .13 & \\
\hline معاونة الزوج زوجته في بيتهما وتربية أبنائهما بالمعروف & .14 & \\
\hline حفظ أسرارها الزوجية & .15 & \\
\hline إمساك الزوجة بمعروف أو تسريحها بإحسان & .16 & \\
\hline طلب الزوجة فسخ النكاح عند الإخلال بالحقوق الزوجية & .17 & \\
\hline 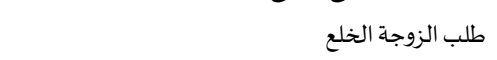 & .18 & \\
\hline طاعة الأولاد للأم في غير معصية & .19 & \\
\hline بر الأولاد للأم والإحسان إليها & .20 & \\
\hline
\end{tabular}




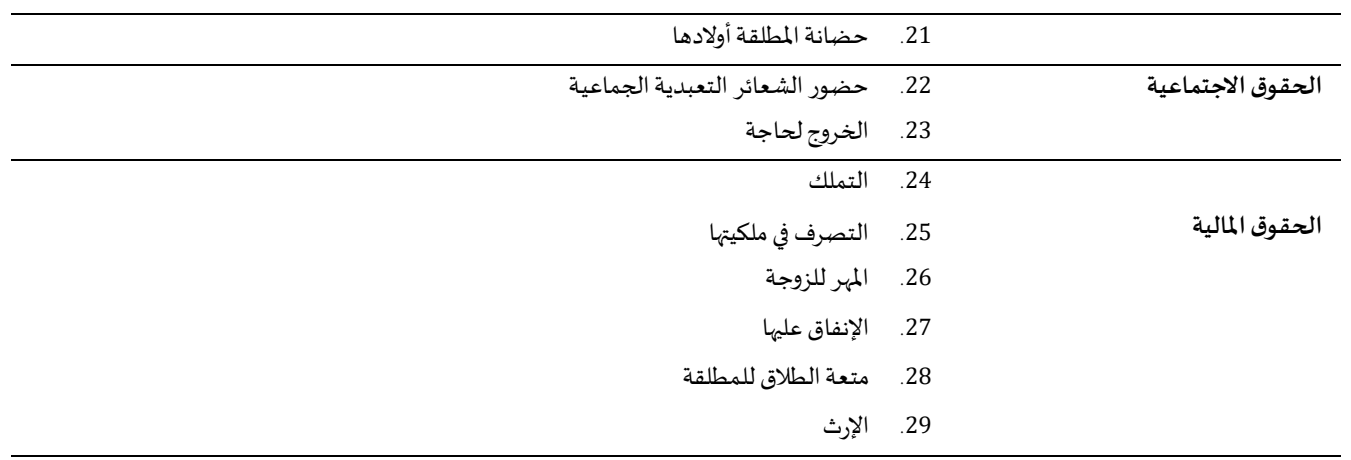

2.3. إجابة السؤال الثاني: ما هي واجبات المرأة في الشريعة الإسلامية التي يجب أن تلم بها الطالبة من خلال مقرر الفقه نظام المقررات في المرحلة

توصل الباحثان إلى الإجابة عن هذا السؤال من خلال الاطلاع على الكتب والمراجع والدراسات والمواقع الإلكترونية التي تناولت مجال واجبات

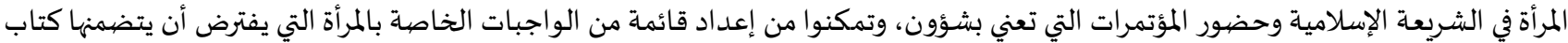
الفقه لطالبات الصف الأول الثانوي، في ضوء آراء مجموعة من المحكمين. جدول (2): قائمة هائية بواجبات المرأة التي يفترض تضمينها في محتوى كتاب الفقه (نظام المقررات) للصف الأول الثانوي

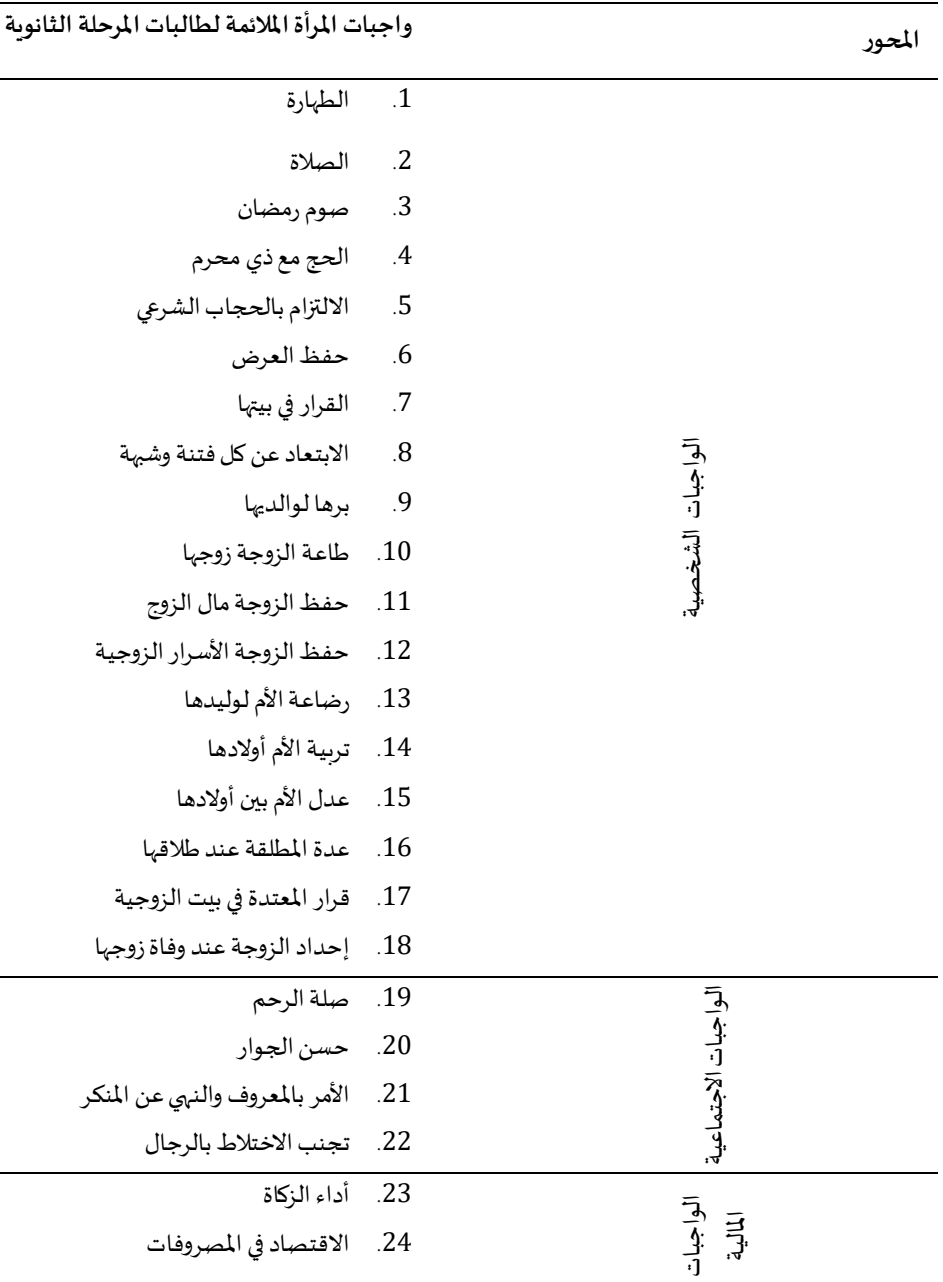

3.3. إجابة السؤال الثالث: ما مدى تو افرحقوق المرأة التي يجب أن تلم بها الطالبة في الصف الأول الثانوي، في كتاب الفقه (نظام المقررات) بالمملكة العربية السعودية؟ المابة 
للإجابة عن هذا السؤال تم حساب التكرارات والنسب المئوية لمعرفة مدى توافر حقوق المرأة في كتاب الفقه نظام المقررات للصف الأول الثانوي من خلال بطاقة تحليل المحتوى . من هندابه يعرض الباحثان بداية النتائج العامة لمدى توافر محاور حقوق المرأة الشخصية والاجتماعية والمالية بشكل عام في كتاب الفقه، يلي ذلك عرض تفصيلي لمدى توافر فئات حقوق المرأة في كتاب الفقه، كالآتي:

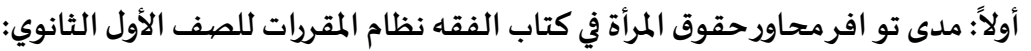
بين الباحثان في هذا الجزء تكرارات و نسب توافر محاور حقوق المرأة بشكل عام في كتاب الفقه نظام المقررات للصف الأول الثانوي ، وذلك على جدول (3): يبين التكرارات والنسب المئوية لمدى تو افر محاورحقوق المرأة في كتاب الفقه نظام المقررات

\begin{tabular}{|c|c|c|}
\hline نسب تو افر المحاور & التكرارات & محاور الحقوق \\
\hline$\% 78.79$ & 26 & الحقوق الشخصية \\
\hline$\% 0.00$ & 0 & الحقوق الاجتماعية \\
\hline$\% 21.21$ & 7 & الحقوق المالية \\
\hline$\% 100.00$ & 33 & المجممع الكلي \\
\hline
\end{tabular}
النحو التالي:

يتضح من الجدول السـابق: أنه بلغ مجموع عدد تكرارات محور الحقوق الشخصية (26) تكراراً، بينما بلغ عدد تكرارات محور الحقوق المالية (7) تكرارات، فيما انعدمت تكرارات محور الحقوق الاجتماعية. ويلاحظ أنه من الممكن ترتيب محاور حقوق المرأة المتضيمنة في كتاب الفقه نظام المقررات للصف المحرات الأول الثانوي ترتيبا تنازلياً حسب نسب توافرها في كتاب الفقاء من الأكبر إلى الأصغر كما يلي: 1. جاء "محور الحقوق الشخصية" بالترتيب الأول من حيث عدد التكرارات التي بلغت (26) تكرارا؛ مما يشكل (78.79 \%) من نسبة محاور حقوق

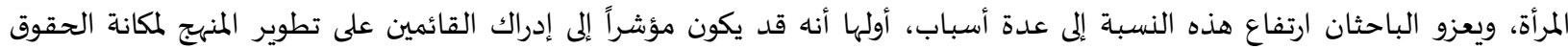

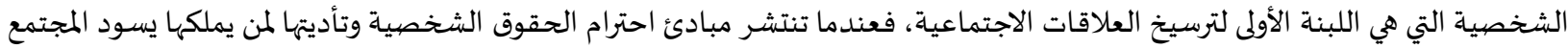
جو من الاحترام والانسجام والألفة. والسبب الثاني قد يكون كما سبقت الإشارة عند الإجابة على السؤال الأول من أسئلة البحث في قائمة " محور الحقوق الشخصية للمرأة " التي تم الاتفاق على ملاءمتها وحاجتها لطالبات الصفف الأول الثانوي والتي بلفت (21) حقاً، كانت الأكثر عدداً من

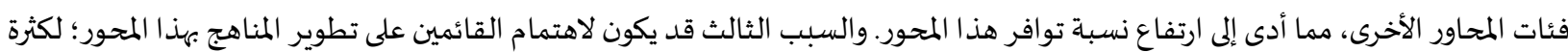

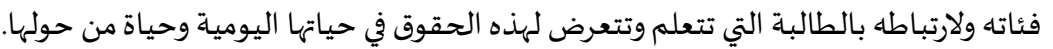

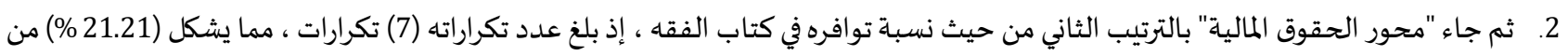

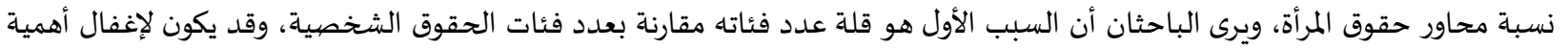

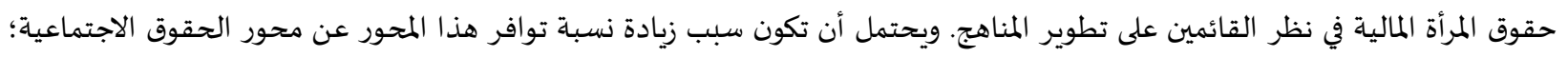
لازدياد قضايا المنازعات المالية اجتماعياً وإعلامياً، وقد يكون حرصاً من القائمين على تطوير المناهج على حفظ هذه الحقوق بالتحديد التي تكثر حولها المشاكل الأسرية و الاجتماعياة. 3. أما محور الحقوق الاجتماعية فلم تتوافر في دروس كتاب الفقه؛ فقد يكون انعدامهاعا لقلة عدد فئاتها التي بلغت اثنتين فقط، وقد يكون غياب

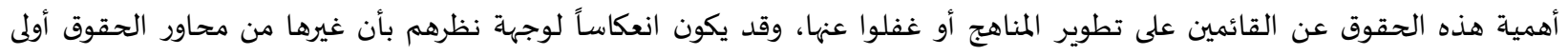

بالتضمين.

ثانياً: مدى تو افرفئات حقوق المرأة في كتاب الفقه نظام المقررات للصيف الأول الثانوي: بين الباحثان في هذا الجزء تكرارات ونسب تضمين فئات حقوق المراة فئئاب المرأة في كتاب الفقه نظام المقررات للصف الأول الثانوي، وذلك على النحو التالي:

\begin{tabular}{|c|c|c|c|c|}
\hline 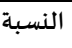 & التكرار & \multicolumn{2}{|c|}{ حقوق المرأة } & المحور \\
\hline 6.06 & 2 & الرفق وحسن المعاملة من ولي أمرها & .1 & \\
\hline 0.00 & 0 & 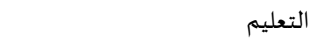 & .2 & s \\
\hline 0.00 & 0 & 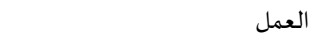 & .3 & 5 \\
\hline 3.03 & 1 & الرعاية الصحية & .4 & $y$ \\
\hline 12.12 & 4 & حسن اختيار والدتها & .5 & \\
\hline
\end{tabular}




\begin{tabular}{|c|c|c|c|c|}
\hline 0.00 & 0 & إثبات نسبها & .6 & \\
\hline 0.00 & 0 & حسن تسميتها & .7 & \\
\hline 0.00 & 0 & تربيتها التربية الصالحة & 8 & \\
\hline 0.00 & 0 & العدل بينها وبين إخوتها ذكورا وإناثا & .9 & \\
\hline 9.09 & 3 & 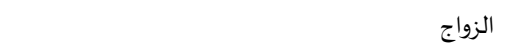 & .10 & \\
\hline 9.09 & 3 & استئذانها عند الزواج & .11 & \\
\hline 6.06 & 2 & المعاشرة بالمعروف للزوجة & .12 & \\
\hline 3.03 & 1 & حق الإنجاب للزوجة ل & .13 & \\
\hline 0.00 & 0 & معاونة الزوج زوجته في بيتهما وتربية أبنائهما بالمعروف & .14 & \\
\hline 0.00 & 0 & حفظ أسرارها الزوجية & .15 & \\
\hline 9.09 & 3 & إمساك الزوجة بمعروف أو تسربحها بإحسان & .16 & \\
\hline 6.06 & 2 & طلب الزوجة فسخ النكاح عند الإخلال بالحقوق الزوجية & .17 & \\
\hline 6.06 & 2 & طلب الزوجة الخلع & .18 & \\
\hline 3.03 & 1 & طاعة الأولاد للأم في غير معصية & .19 & \\
\hline 3.03 & 1 & بر الأولاد للأم والإحسان إلهها & .20 & \\
\hline 3.03 & 1 & حضانة المطلقة أولادها & .21 & \\
\hline 0.00 & 0 & حضور الشعائر التعبدية الجماعية & .22 & $\bar{s}$ \\
\hline 0.00 & 0 & الخروج لحاجة & .23 & 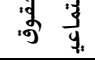 \\
\hline 3.03 & 1 & التملك & .24 & \multirow{6}{*}{$\begin{array}{l}\overline{9} \\
\text { '. } \\
\bar{g} \\
\overline{3}\end{array}$} \\
\hline 0.00 & 0 & التصرف في ملكيتها & .25 & \\
\hline 3.03 & 1 & المهر للزوجة & .26 & \\
\hline 9.09 & 3 & الإنفاق عليها & .27 & \\
\hline 6.06 & 2 & متعة الطلاق للمطلقة & .28 & \\
\hline 0.00 & 0 & الإرث & .29 & \\
\hline 100.00 & 33 & & & المجموع \\
\hline
\end{tabular}

يتضح من الجدول السابق أن عدد تكرارات حقوق المرأة الملائمة لطالبات المرحلة الثانوية التي تم تضمينها في كتاب الفقه نظام المقررات للصف الأول الثانوي هي: (33) تكراراً. وقد بلغت عدد الحقوق المتضمنة ( 17) حقاً فقط من مجموع (29) حقاً من حقوق المرأة التي يجب أن تلم بها طالبة الصف الأول الثانوي؛ مما يشكل نسبة (58\%) من حقوق المرأة. ويلاحظ أنه من الممكن ترتيب حقوق المرأة المندرجة في دروس كتاب المكأ الفقه نظام المقررات للصف الأول الثانوي ترتيبا تنازلياً من الأكبر إلى الأصغر

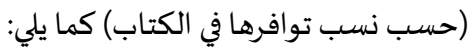

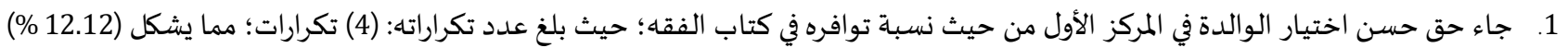

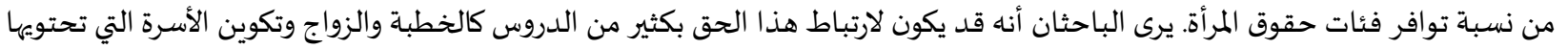

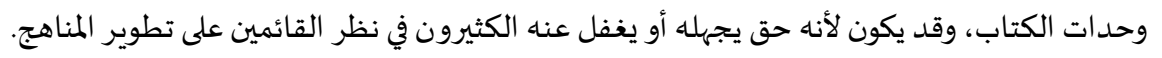

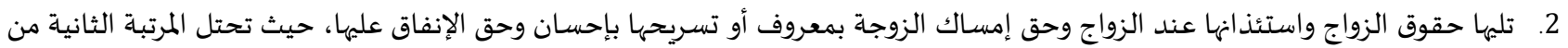

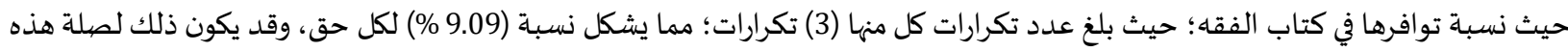

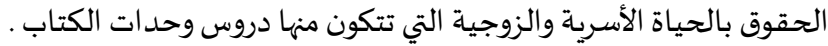

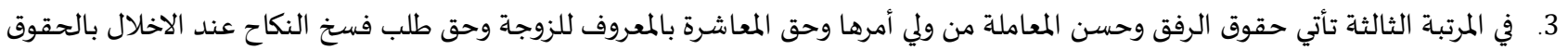

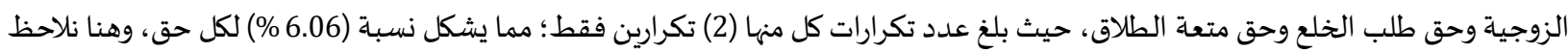
أنه قلت النسب لتوافر هذه الحقوق، قد يكون انعكاسا لوجهاة نظر القائمين على تطوير المناهج بأن هذه الحقوق وقائية وعلاجية لبعض المشاكل

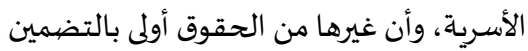

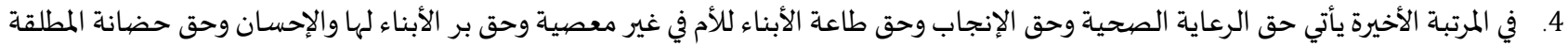

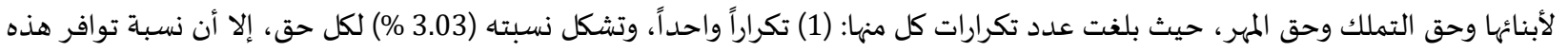

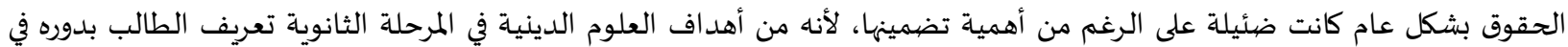


مجتمعه الخاص من حيث هو عضو فياه له حقوقه وعليه واجباته، فيكفل له النفع الخاص ويراعى الصالح العام، وبث روح اليقين في نفوس

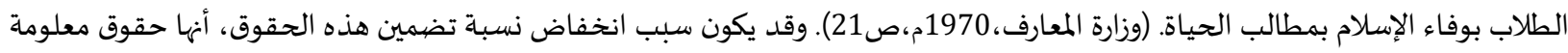
اجتماعيا ومتعارف عليها؛ مما قلل الاهتمام بها في نظر القائمين على تطوير المناهج.

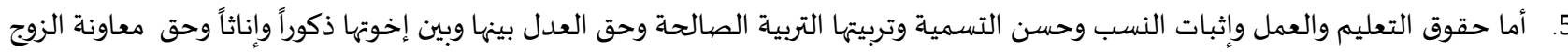
لها في بيتهما وتربية أبنائهما بالمعروف وحق واتئ حفظ أسرارها الزوجية (وهي من الحقوق الشخصية)، وحق حضيور الشعائر التعبدية الجماعية وحق

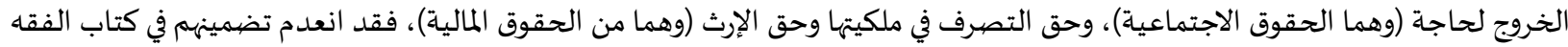

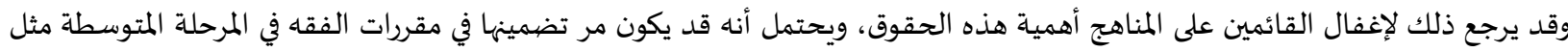
حق التعليم وحق إثبات النسب وحق حسن التسمية وحق التربية الصالحة وحق العدل بينها وبين إخوتها، أما حق العمل وحق معاونة الزوج

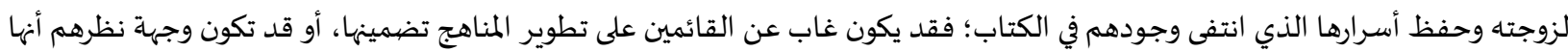

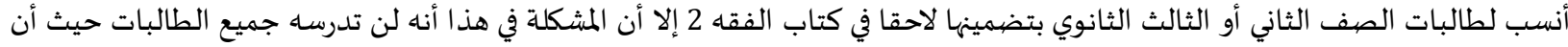

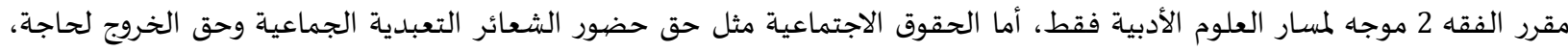

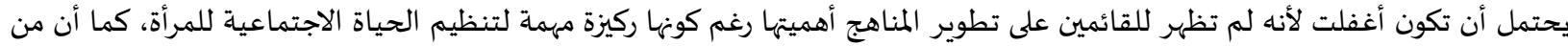
أهداف العلوم الدينية في المرحلة الثانوية هي تعريف الطلاب بقواعد التعامل الاجتماعي وأصهول العلاقات بين الناس ، وتعريفه بدوره في المجتمع

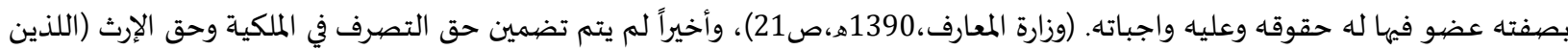

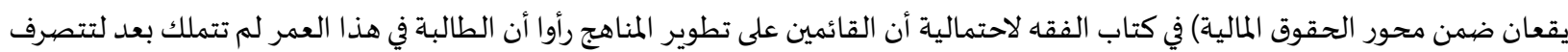

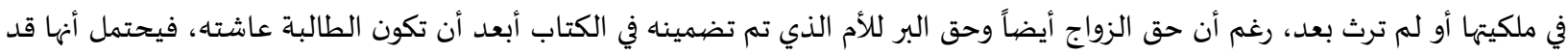

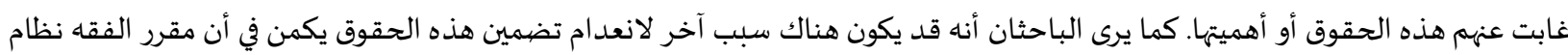

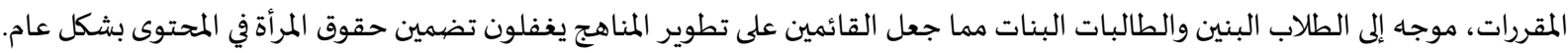
4.3. إجابة السؤال الر ابع: ما مدى تو افرواجبات المرأة التي يجب أن تلم بها الطالبة في الصف الأول الثانوي، في كتاب الفقه (نظام المقررات) بالمملكة العربية السعودية؟ للإجابة عن هذا السؤال تم حساب التكرارات والنسب المئوية لمعرفة مدى توافر واجبات المرأة في كتاب الفقه نظام المقررات للصف الأول الثانوي من خلال بطاقة تحليل المحتوى.

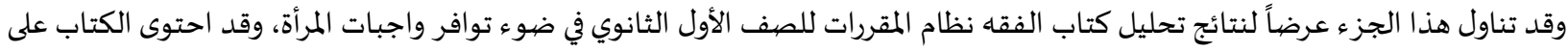
إحدى عشر وحدة، مقسمة إلى ثمانين درساً. وقام الباحثان بعرض نتائج البحث ومناقشتها، بدءءاً بمدى توافر محاور الواجبات الشخصية درسية والاجتماعية والمالية للمرأة بشكل عام في كتاب

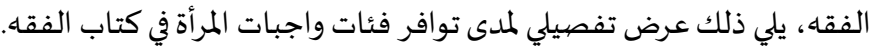

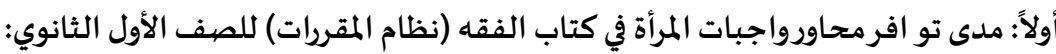
بين الباحثان في هذا الجزء تكرارات و نسب توافر محاور واجبات المرأة بشكل عام في كتاب الفقه (نظام المقررات) للصف الأول الثانوي، وذلك على النحو التالي: جدول (5): يبين التكرارات والنسب المئوية لمدى تو افر محاورواجبات المرأة في كتاب الفقه (نظام المقررات)

\begin{tabular}{|c|c|c|}
\hline نسب تو افر المحاور & التكرارات & محاور الواجبات \\
\hline$\% 81.48$ & 22 & الواجبات الشخصية \\
\hline$\% 7.41$ & 2 & الواجبات الاجتماعية \\
\hline$\% 11.11$ & 3 & الواجبات المالية \\
\hline$\% 100.00$ & 27 & المجموع الكلي \\
\hline
\end{tabular}

يتضح من الجدول السابق: أنه بلغ مجموع عدد تكرارات محور الواجبات الشخصية (22) تكراراً، بينما بلغ عدد تكرارات محور واجبات المالية (3) تكرارات، وبلغ عدد تكرارت محور الواجبات الاجتماعية (2) تكرارين .

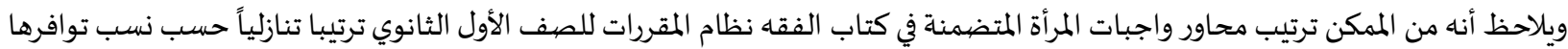
في كتاب الفقه من الأكبر إلى الأصغر كما يلي:

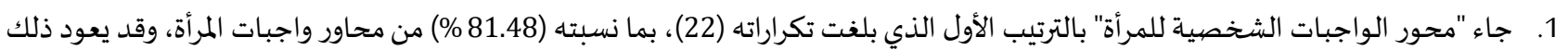
لاهتمام القائمين على تطوير المناهج بما يتعلق بالحياة الشخصية للطالبة وما يجب عليها أن تتعلماه من تلك الواجبات، كما أن عدد فئات محاور 
الواجبات الشخصية يصل إلى 18 واجباً كما سبقت الإشارة إليه عند الإجابة على السؤال الثاني من أسئلة البحث؛ مما يجعله سبباً في ارتفاع نسبة توافره مقارنة بالمحاور الأخرى.

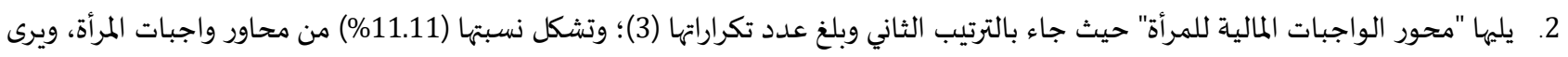
الباحثان أن انخفاض نسبة توافرها في الكتاب قد يرجع لسببين أولهما، قلة عدد فئات هذا المحور الذي يصل إلى فئتين فقط، وقد يكون لحرص

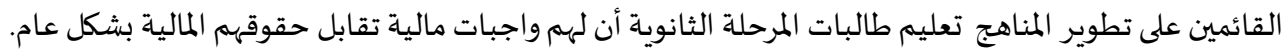
3. ثم يأتي محور الواجبات الاجتماعية في الترتيب الثالث والأخير الذي بلغت تكراراته (2) فقط، ونسبته هي (7.41 \%) من محاور واجبات الماتهات المرأة، يعزو

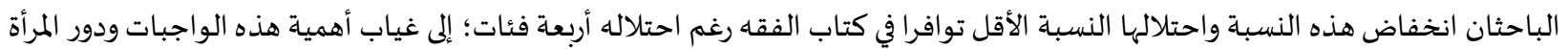
اجتماعيا عن تصور القائمين على تطوير المناهج أو لعدم اهتمامهه بها، إلا أن المأمول أن ترتفع هذه النسبة. ثانياً: مدى تو افرفئات واجبات المرأة في كتاب الفقه (نظام المقررات) للصفي تهور الأول الثانوي: بين الباحثان في هذا الجزء تكرارات ونسب تضمين فئات واجبات المرأة في كتاب الفقه نظام المقررات للصف الأول الثانوي، وذلك على النحو

جدول (6): يبين التكرارات والنسب المئوية لمدى تو افرفئات واجبات المرأة في كتاب الفقه (نظام المقررات) التالي:

\begin{tabular}{|c|c|c|c|c|}
\hline النسبة الن & التكرار & واجبات المرأة & & المحور \\
\hline 3.70 & 1 & 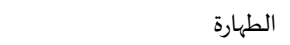 & .1 & \multirow{18}{*}{ 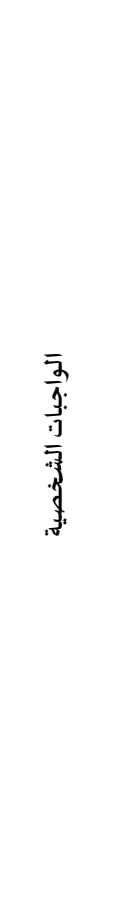 } \\
\hline 0.00 & 0 & 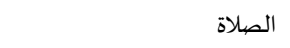 & .2 & \\
\hline 0.00 & 0 & صوم رمضان & 3 & \\
\hline 3.70 & 1 & الحج مع ذي محرم & .4 & \\
\hline 7.41 & 2 & الالتزام بالحجاب الشرعي & .5 & \\
\hline 3.70 & 1 & حفظ العرض & 6 & \\
\hline 3.70 & 1 & القرار في بيتها & .7 & \\
\hline 3.70 & 1 & الابتعاد عن كل فتنة وشبهة & 8 & \\
\hline 0.00 & 0 & برها لوالديها & .9 & \\
\hline 3.70 & 1 & طاعة الزوجة زوجها & .10 & \\
\hline 7.41 & 2 & حفظ الزوجة مال الزوج & .11 & \\
\hline 0.00 & 0 & حفظ الزوجة الأسرار الزوجية & .12 & \\
\hline 7.41 & 2 & رضاعة الأم لوليدها & .13 & \\
\hline 7.41 & 2 & تربية الأم أولادها & .14 & \\
\hline 0.00 & 0 & عدل الأم بين أولادها & .15 & \\
\hline 14.81 & 4 & عدة المطلقة عند طلاقها & .16 & \\
\hline 7.41 & 2 & قرار المعتدة في بيت الزوجية & .17 & \\
\hline 7.41 & 2 & إحداد الزوجة عند وفاة زوجها & .18 & \\
\hline 0.00 & 0 & صلة الرحم & .19 & \multirow{4}{*}{ 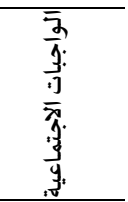 } \\
\hline 0.00 & 0 & حسن الجوار & .20 & \\
\hline 3.70 & 1 & الأمر بالمعروف والنهي عن المنكر & .21 & \\
\hline 3.70 & 1 & تجنب الاختلاط بالرجال & .22 & \\
\hline 0.00 & 0 & أداء الزكاة & .23 & \multirow{2}{*}{$\overline{\bar{g}} \overline{\overline{3}}$} \\
\hline 11.11 & 3 & الاقتصاد في المصروفات & .24 & \\
\hline 100.00 & 27 & & & المجموع \\
\hline
\end{tabular}

يتضح من الجدول السابق أن عدد تكرارات واجبات المرأة الملائمة لطالبات المرحلة الثانوية التي تم تضمينها في كتاب الفقه 1 نظام المقررات للصف الأول الثانوي بلغت: (27) تكراراً. وقد بلغت عدد الواجبات المتضمنة (16) واجباً فقط من مجموع (24) واجب من واجبات المرأة التي يجب أن تلم بها طالبة الصفف الأول الثانوي؛ مما يشكل نسبة (66 \%) من واجبات المرأة. 
ويود الباحثان أن يلفتا النظر هنا إلى أنها لم تتوزع هذه الواجبات على الثمانون درساً توزيعاً متوازناً، إنما تركزت وتكررت في وحدات معينة محور

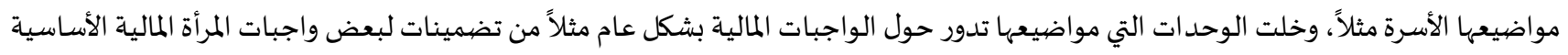
مثل واجب الزكاة.

ويلاحظ أنه من الممكن ترتيب واجبات المرأة المندرجة في دروس كتاب الفقه نظام المقررات للصف الأول الثانوي ترتيبا تنازلياً من الأكبر إلى

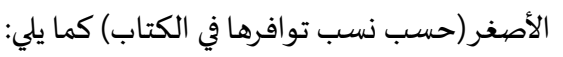

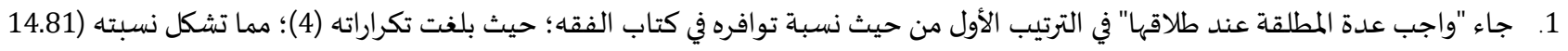

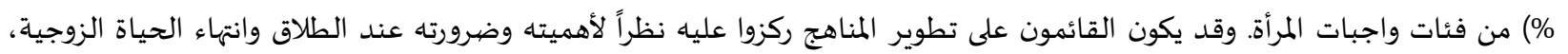

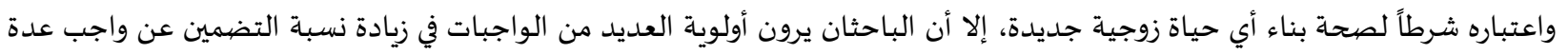

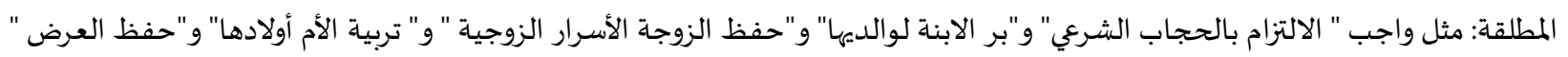

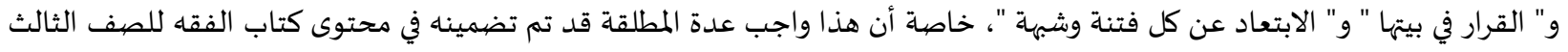

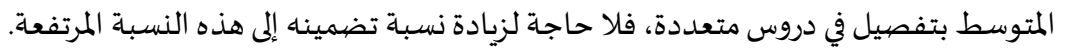

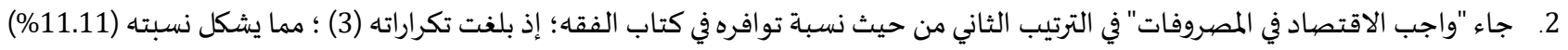

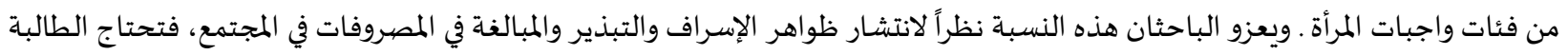

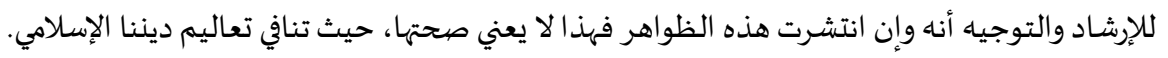

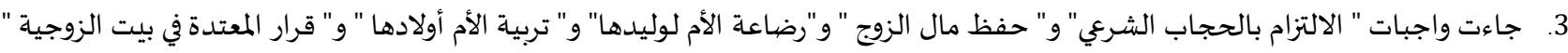

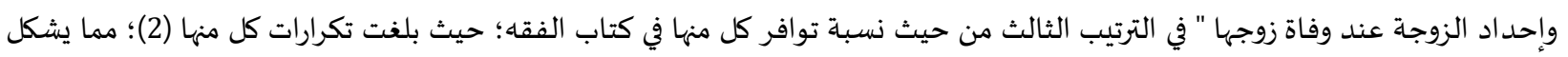

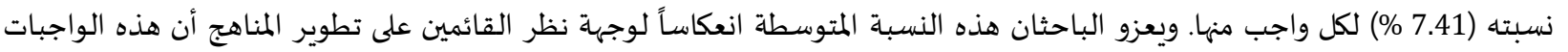

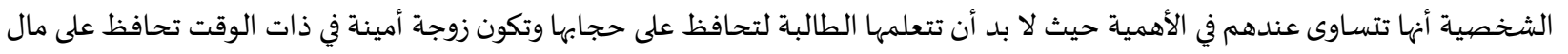

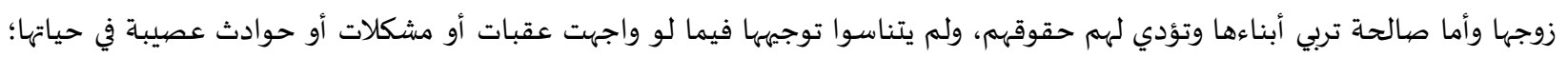

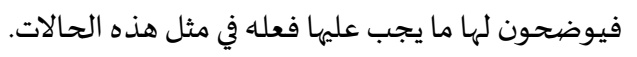

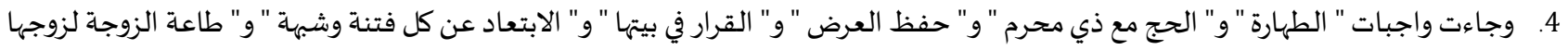

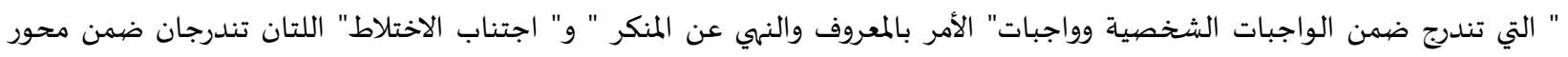

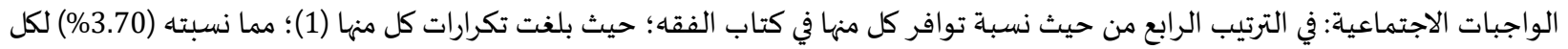

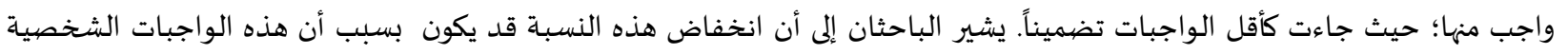

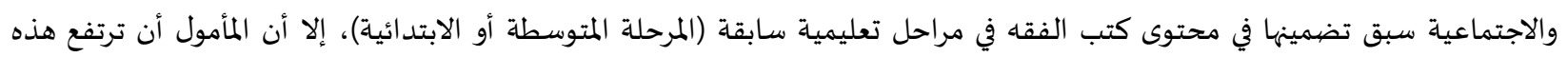

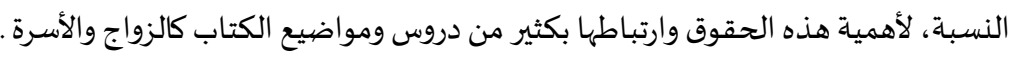

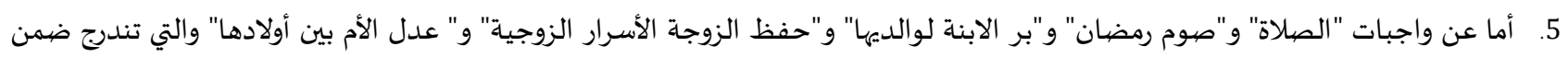

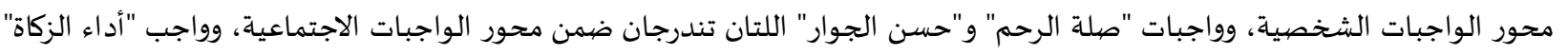

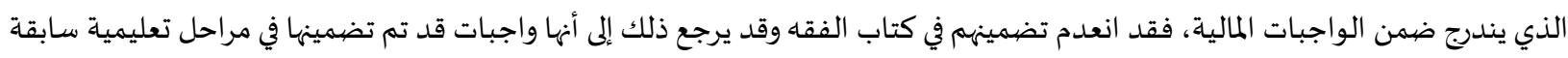

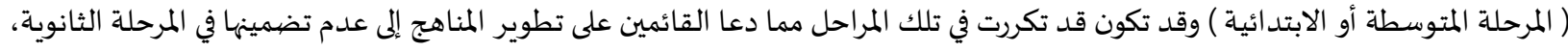

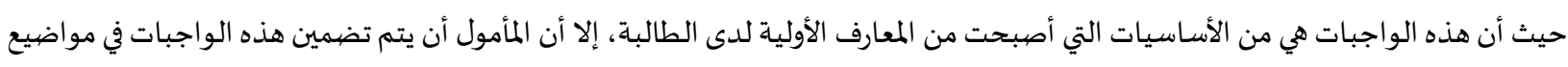

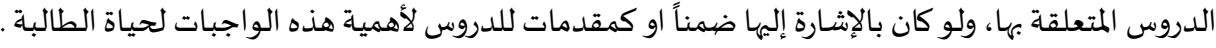

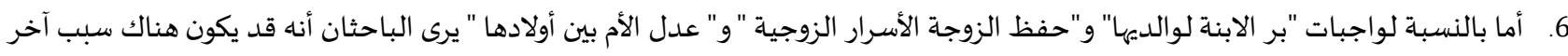

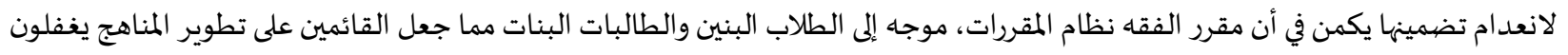

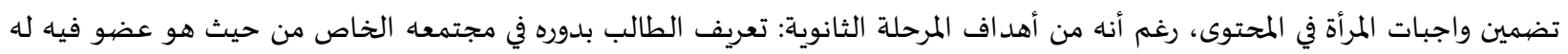

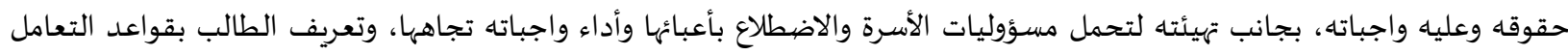

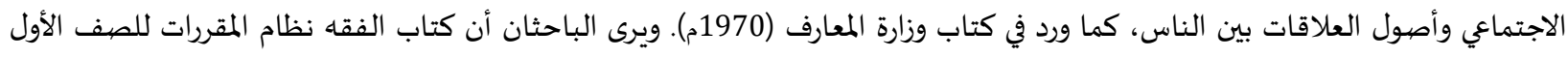

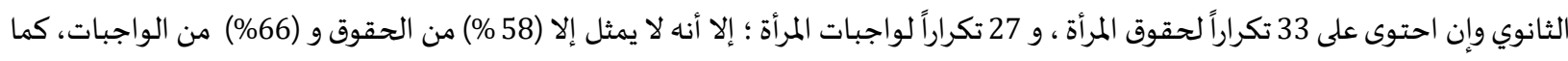

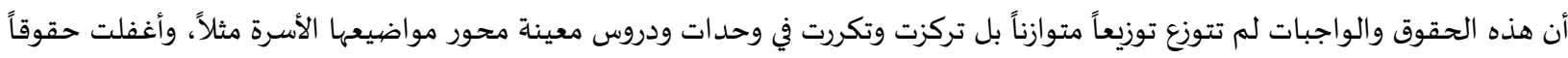

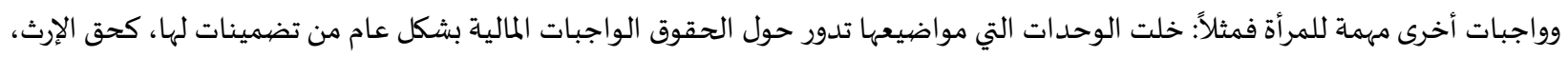
وواجب الزكاة. وبذلك لم يتضمن الكتاب إلا 62\% من مجموع حقوق وواجبات المرأة التي يجب أن تلم بها طالبة الصف الهات الأول الثانوي. 
5.3. إجابة السؤال الخامس: ما الآثار المترتبة على دمج كتب الفقه للبنين والبنات في المرحلة الثانوية في تضمنها للحقوق والواجبات التي يجب أن

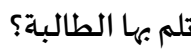

توصل الباحثان إلى بعض الآثار التي ترتبت على دمج كتب الفقه للبنين والبنات في المرحلة الثانوية ، ومن تلك الآثار ما يلي:

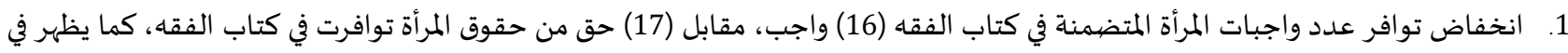

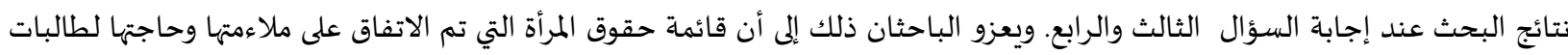

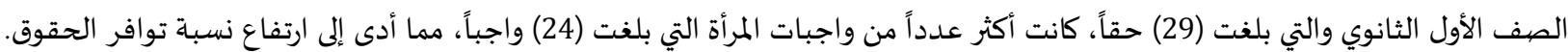

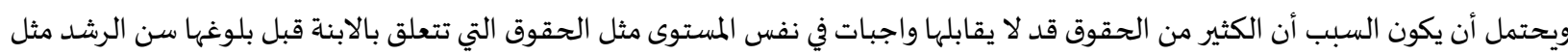
حق الرفق وحسن المعاملة وحق حسن اختيار الوالدة وحق حسن التسمية وحق التعليم وحق الرعاية الصحية وحق التربية وحق التحان الإنفاق، كلها

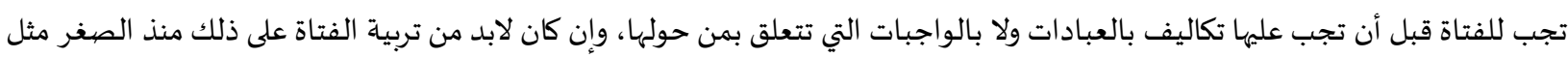

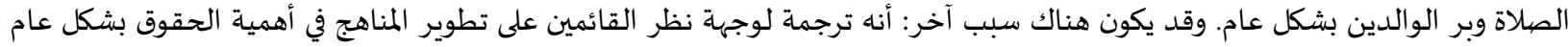

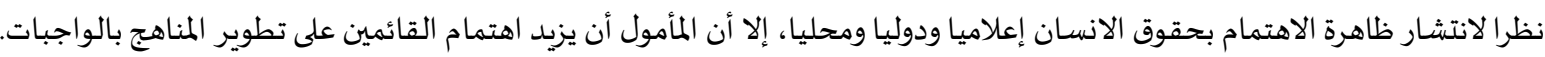

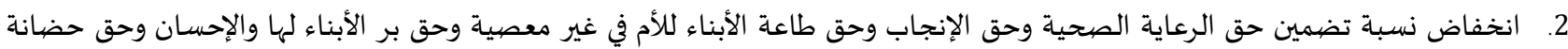

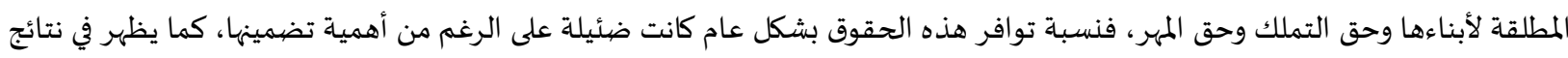
البحث عند إجابة السؤال الثالث.

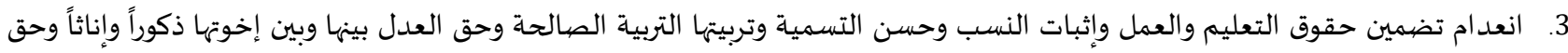

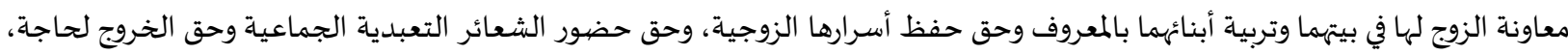

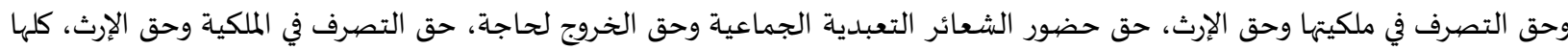

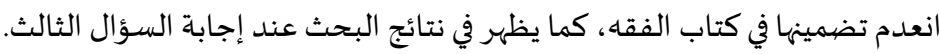

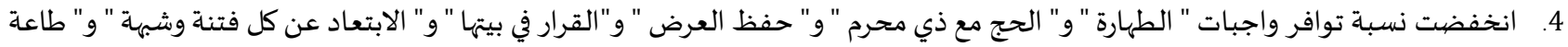

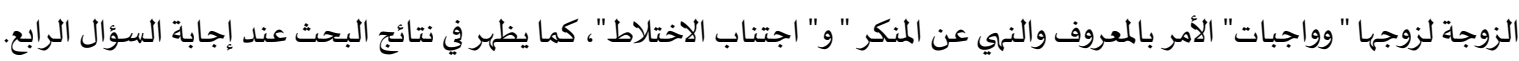

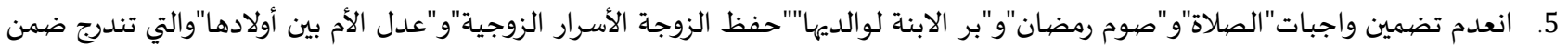

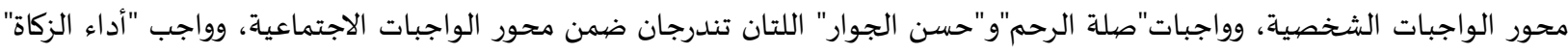

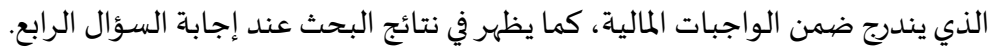

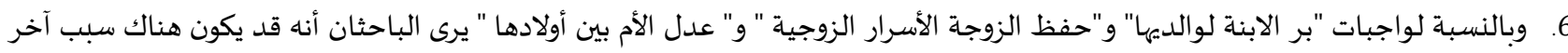

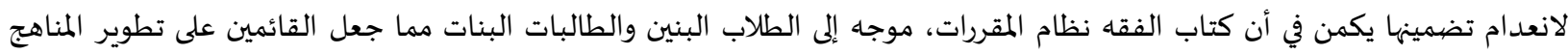

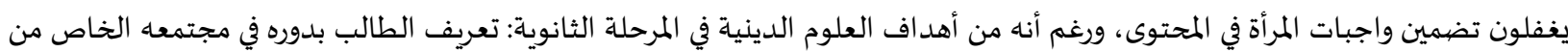

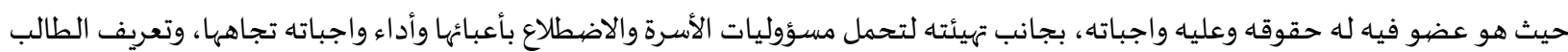

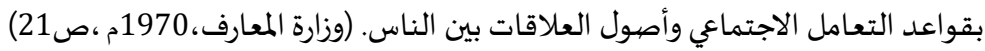
6.3. إجابة السؤال السادس: ما التوصيات والمقترحات لتحسين تضمين حقوق وواجبات المرأة في الشريعة الإسلامية والتي يجب أن تلم بها الطالبة

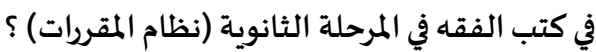
من خلال نتائج البحث يرى الباحثان مقترحات لتحسين تضمين حقوق وواجبات المرأة في كتب الفقها في المرحلة الثانوية (نظام المقررات) وهي

أن يراعي مؤلفو الكتب الدراسية تضمين حقوق وواجبات المرأة في محتوى كتاب الفقها وزيادة نسبة تضمين الواجبات الخاصة المرأة التي تحتاجها

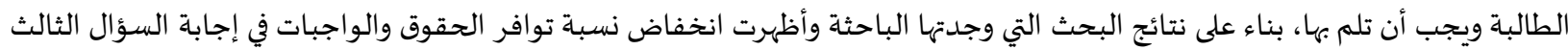

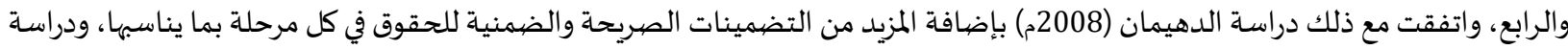

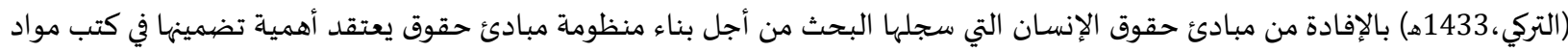

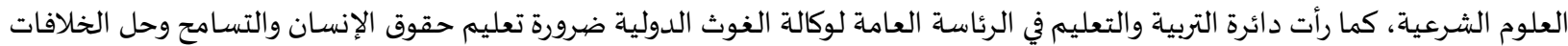

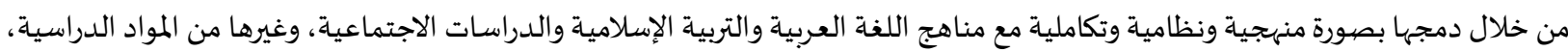
وبذلك فلن يتم تخصيص حصص منفردة لتدريس هذه الموضوعات، وإنما سوف يتم دمجها وتدريسها من خلال الحصص المقررة لكل من اللغة

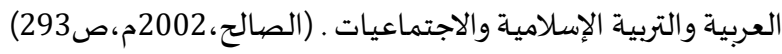


زيادة نسبة تضمين حق الرعاية الصحية وحق الإنجاب وحق طاعة الأبناء للأم في غير معصية وحق بر الأبناء لها والإحسان وحق حضانة المطلقة لأبنائها وحق التملك وحق المهر، بناء على نتائج البحث التي وجدتها الباحثة و اظهرت انخفاضها في إجابة إنهابة السؤال الثالث. زيادة ذسبة تضمين حقوق التعليم والعمل وإثبات النسب وحسن التسمية وتربيتها التربية الصالحة وحق العدل بينها وبين إخوتها ذكوراً وإناثاً وحق

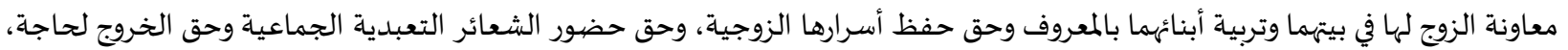
وحق التصرف في ملكيتها وحق الإرث، حق حضور الشعائر التعبدية الجماعية وحق الخروج لحاجة، حق التصرف في الملكية وحق الإرث، بناء على

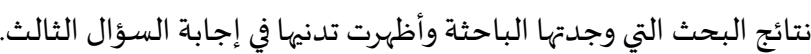

زيادة ذسبة تضمين واجبات " الطهارة " و" الحج مع ذي محرم " و" حفظ العرض " و" القرار في بيتها " و" الابتعاد عن كل فتنة وشبهة "و" طاعة

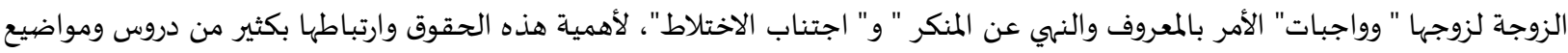

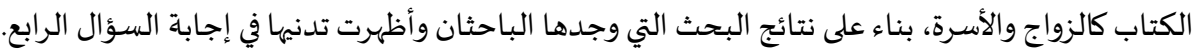
المأمول أن يتم تضمين واجبات "الصلاة" و"صوم رمضان" و"بر الابنة لوالديها" و"حفظ الزوجة الأسرار الزوجية " و" عدل الأم بين أولادها"،

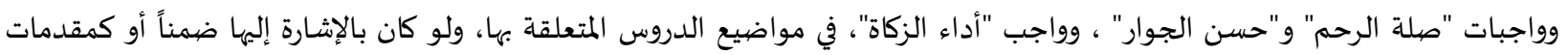
للدروس لأهمية هذه الواجبات لحياة الطالبة، بناء على نتائج البحث التي وجدها الباحثان و أظهرت انعدامها في إجابة السؤال الرابع. أن تكون لغة الخطاب موجهة للطالبات بصيغة المؤنث في سياق المحتوى وعند صياغة الأهداف والأنشطة، وأن يتم الفصل في المقررات الموجهة للإناث عن تلك الموجهة للذكور، واعادة بناء استراتيجية تعليم المرأة، كما نصيت عليها رؤى وثيقة حقوق المرأة وواجباتهاتها في الإسلام.

في ضوء النتائج التي توصل إليها الباحثان يوضَى بما يلي: أن يراعي مؤلفو الكتب الدراسية تضمين حقوق وواجبات المرأة في محتوى كتاب الفقه نظام المقررات للصف الأول الثانوي بالمملكة العربية السعودية، وبخاصة الحقوق والواجبات التي لم يتضمنها محتوى الكتاب وهي: "حق التعليم " و"حق العمل"و" حق إثبات النسب للابنة" و" حق

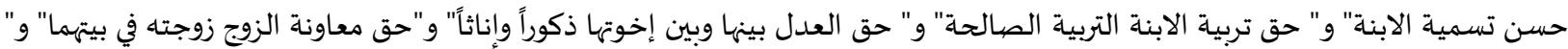

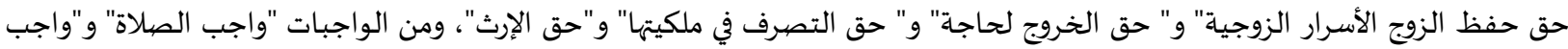

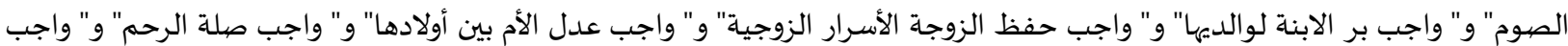
حسن الجوار" و"واجب الزكاة". ويمكن إعادة النظر في محتوى مقرر الفقه 1 نظام المقررات لطالبات المرحلة الثانوية بما يحقق التضمين المطلوب لحقوق وواجبات المرأة، وإضافة المزيد من التضمينات لحقوق وواجبات المرأة الملائمة لطالبات المرحلة الثانوية. ضرورة زيادة الاهتمام بحقوق المرأة، مثل حق التعليم والعمل والتصرف في ملكيتها والإرث؛ حيث تمثل هذه الحقوق أهم حقوق المرأة، وضرورة

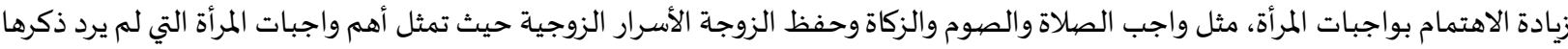
في الكتاب.

العناية بحقوق وواجبات المرأة في مقررات العلوم الشرعية بما يتناسب مع المرحلة الدراسية والعمرية للطالبات. توعية معلمات الفقاه بأهمية حقوق وواجبات المرأة عند تناول هذا المقرر، وكيفية إكسابها للطالبات. التركيز على أهمية الحقوق والواجبات في برامج إعداد معلمات العلوم الشرعية في كليات التربية، بحيث يصبحن قادرات على إكسابها للطالبات من خلال الكتاب المدرسي. إعادة صياغة لغة الكتاب بما يخاطب الطالبة بصيغة المؤنث لأهميته في شعور الطالبة بأنها هي المخاطبة، بالإضافة إلى تعديل وتحويل الأنشطة

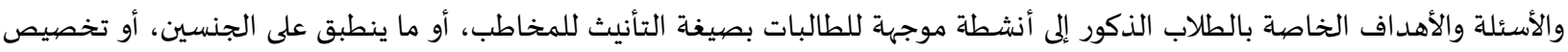
الطالبات بكتب لمقررات جميع المواد في جميع المراحل تحتوي على صيغة التأنيث للمخاطب، والفصل في المقررات الموجهة للإناث عن تلك الموجهة

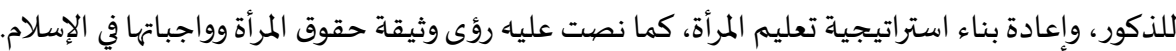
ضرورة إعادة النظر في خطط تعليم المرأة، بحيث تتفق مع طبيعة المرأة من ناحياة، وظروف المجتمع، واحتياجات التنمية من ناحية أخرى. تضمين مناهج التعليم بشكل عام في المرحلة الثانوية -كصيغة مقترحة- على :المفهوم الشرعي للعلاقة بين الرجل والمرأة، وحقوق كل منهما وواجباته، والوسائل الفعالة في تربية الأولاد، وعلاج المشكلات المرحسئ 
1. التركي، منى حسين تركي(2010). مدى تضمين وثيقة منهج مواد العلوم الشرعية في التعليم الأساسي لمبادئ حقوق الإنسان. رسالة ماجستير غير

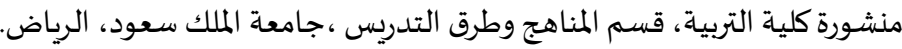

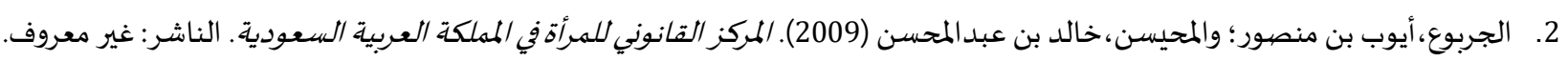

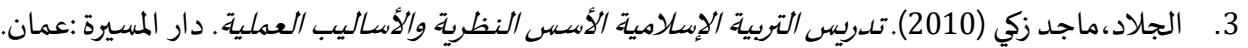

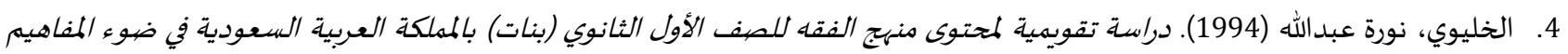

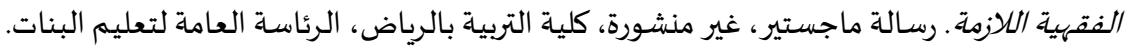

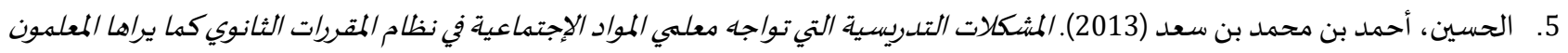

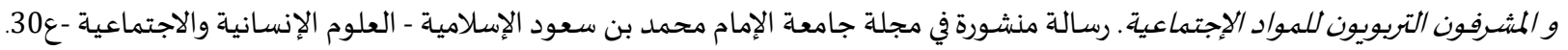

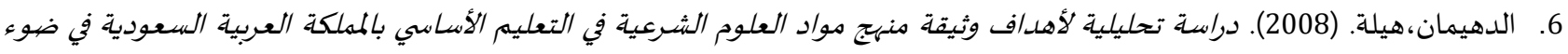

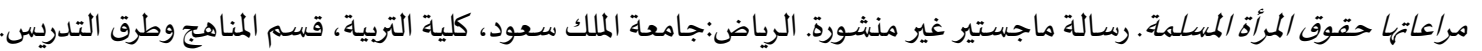

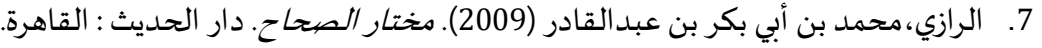

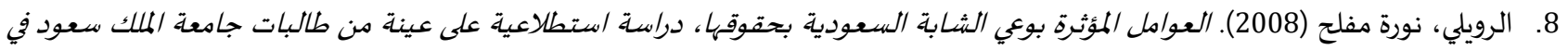
مدينة الرياض. رسالة ماجستير غير منشورة. كلية الآداب. قسم الدراسات الاجتماعية.

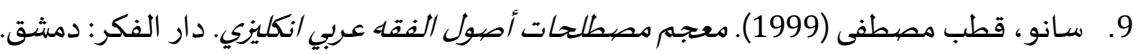

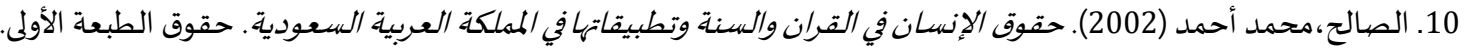

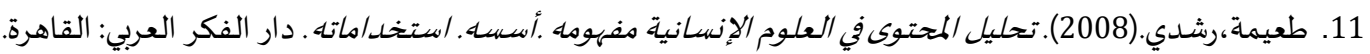

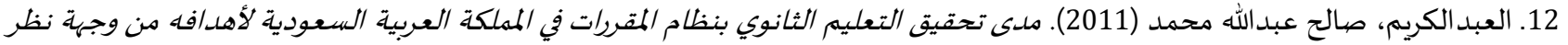

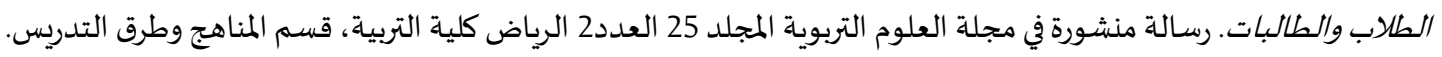

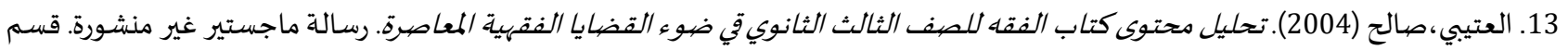
المناهج وطرق التدريس جامعة الملك سعود، كلية التربية: الرياض.

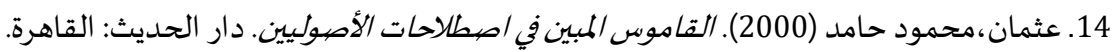

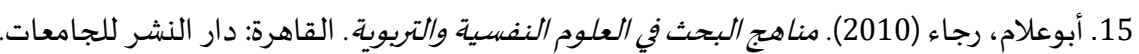

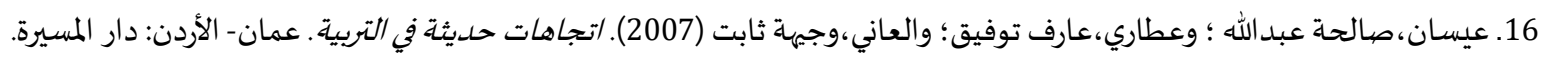

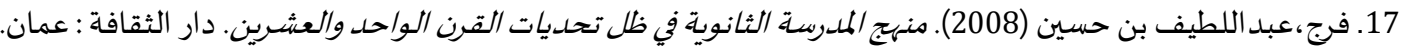

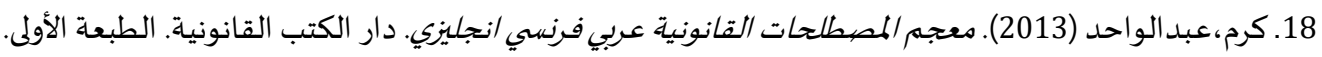

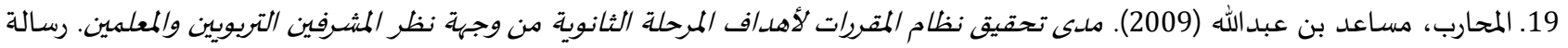
ماجستير غير منشورة. كلية التربية، قسم المناهج وطرق التدريس. 20. محمد، الزاكي، منى مصطفى (2013). إدراك الزوجة لحقوقها وواجباتها (في ضوء الكتاب والسنة) وعلاقته بجودة حياتها. رسالة منشورة. مجلة علوم وفنون- دراسات وبحوث- مصر.

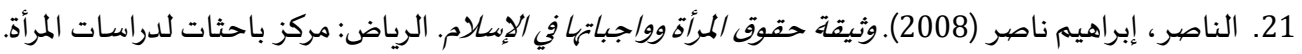

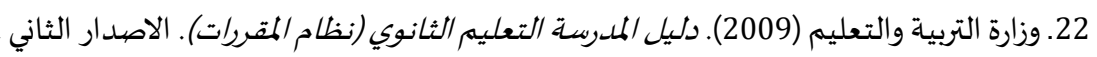

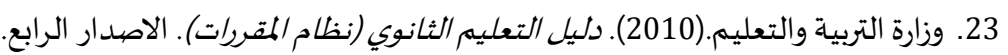
24. وزارة المعارف (1970). سياسة التعليم في المملكة العربية السعودية. 
ثانياً: المراجع الأجنبية:

1. Hannallah \& Guirguis,Ramzi Kamel \& MichaelTakla.(1998). Dictionary of the terms of education.Librairie du Liban publishers. Encyclopædia Britannica, Secondary education, 2014

ثالثاً: المو اقع الإلكترونية:

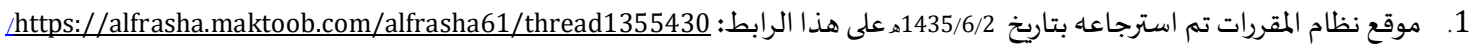

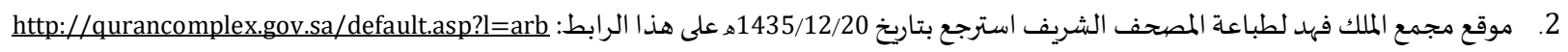


المجلة الدولية للدراسـات التربوية والنفسية

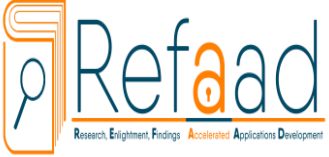

www.refaad.com
International Journal of Educational \& Psychological Studies (EPS)

Journal Homepage: https://www.refaad.com/views/EPSR/Home.aspx

ISSN: 2520-4149 (Online) 2520-4130 (Print)

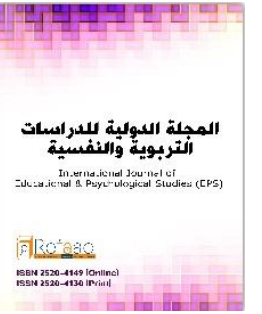

\section{The rights and duties of women included in the book of Fiqh (curriculums system) for the students of the first grade of secondary school}

\section{Yara Abdulmajeed Alabdulkareem}

Lecturer of Curriculum and instruction-College of education-King Saud University yalabdulkareem@ksu.edu.sa

\section{Tawfeeg Albedewi}

Associate professor of Curriculum and instruction-College of education-King Saud University

Received : 18/11/2020 Revised : 16/12/2020 Accepted :6/3/2021 DOI : https://doi.org/10.31559/EPS2021.10.1.4

Abstract: This research is about "The rights and duties of women included in the book of Fiqh (curriculums system) for the students of the first grade of secondary school", and the aim of the research was to identify how frequent the Fiqh book (curricula system) for the first grade of secondary schools in Saudi Arabia includes women's rights and duties in Islamic law, which must be grasped by a student at the secondary level. The most important results of the research were that the Fiqh Book in secondary education (curricula system) joint program included only (62\%) of women's rights and duties is included in the book.

The most important recommendations and suggestions were: The authors of textbooks must consider including women's rights and duties in the content of the book of Fiqh -1 - (curricula system) for secondary school students in Saudi Arabia, Paraphrasing the textbook to address the female student which is significant to ensure that the student is the right addressee.

Keywords: rights and duties of women; curriculums system; the first grade of secondary school.

\section{References:}

1. Al'bdalkrym, Salh 'bdallh Mhmd (2011). Mda Thqyq Alt'lym Althanwy Bnzam Almqrrat Fy Almmlkh Al'rbyh Als'wdyh Lahdafh Mn Wjht Nzr Altlab Waltalbat. Rsalt Mnshwrh Fy Mjlt Al'lwm Altrbwyh Almjld 25 Al'dd2 Alryad Klyt Altrbyh, Qsm Almnahj Wtrq Altdrys.

2. Abw'lam, Rja' (2010). Mnahj Albhth Fy Al'lwm Alnfsyh Waltrbwyh. Alqahrh: Dar Alnshr Lljam'at.

3. Al'tyby,Salh (2004). Thlyl Mhtwa Ktab Alfqh Llsf Althalth Althanwy Qy Dw' Alqdaya Alfqhyh Alm'asrh. Rsalt Majstyr Ghyr Mnshwrh. Qsm Almnahj Wtrq Altdrys Jam't Almlk S'wd, Klyt Altrbyh: Alryad.

4. 'thman,Mhmwd Hamd (2000). Alqamws Almbyn Fy Astlahat Alaswlyyn. Dar Alhdyth: Alqahrh.

5. 'ysan,Salhh 'bdallh; W'tary,'arf Twfyq; Wal'any, Wjyhh Thabt (2007). Atjahat Hdythh Fy Altrbyh. 'man- Alardn: Dar Almsyrh.

6. Aldhyman,Hylh. (2008). Drash Thlylyh Lahdaf Wthyqh Mnhj Mwad Al'lwm Alshr'yh Fy Alt'lym Alasasy Balmmlkh Al'rbyh Als'wdyh Fy Dw' Mra'atha Hqwq Almrah Almslmh. Rsalt Majstyr Ghyr Mnshwrh. Alryad:Jam't Almlk S'wd, Klyt Altrbyh, Qsm Almnahj Wtrq Altdrys .

7. Frj,'bdalltyf Bn Hsyn (2008). Mnhj Almdrsh Althanwyh Fy Zl Thdyat Alqrn Alwahd Wal'shryn. Dar Althqafh: 'man.

8. Alhsyn, Ahmd Bn Mhmd Bn S'd (2013). Almshklat Altdrysyh Alty Twajh M'lmy Almwad Alejtma'yh Fy Nzam Almqrrat Althanwy Kma Yraha Alm'lmwn W Almshrfwn Altrbwywn Llmwad Alejtma'yh. Rsalt Mnshwrh Fy Mjlt Jam't Alemam Mhmd Bn S'wd Aleslamyh - Al'lwm Alensanyh Walajtma'yh -'30.

9. Aljlad,Majd Zky (2010). Tdrys Altrbyh Aleslamyh Alass Alnzryh Walasalyb Al'mlyh. Dar Almsyrh:'man.

10. Aljrbw', Aywb Bn Mnswr; Walmhysn,Khald Bn 'bdalmhsn (2009). Almrkz Alqanwny Llmrah Fy Almmlkh Al'rbyh Als'wdyh. Alnashr: Ghyr M'rwf.

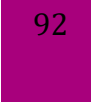


11. Alkhlywy, Nwrh 'bdallh (1994). Drash Tqwymyh Lmhtwa Mnhj Alfqh Llsf Alawl Althanwy (Bnat) Balmmlkh Al'erbyh Als'wdyh Fy Dw' Almfahym Alfqhyh Allazmh. Rsalt Majstyr, Ghyr Mnshwrh, Klyt Altrbyh Balryad, Alr'ash Al'amh Lt'lym Albnat.

12. Krm,'bdalwahd (2013). M'jm Almstlhat Alqanwnyh 'rby Frnsy Anjlyzy. Dar Alktb Alqanwnyh. Altb'h Alawla.

13. Almharb, Msa'd Bn 'bdallh (2009). Mda Thqyq Nzam Almqrrat Lahdaf Almrhlh Althanwyh Mn Wjht Nzr Almshrfyn Altrbwyyn Walm'Imyn. Rsalt Majstyr Ghyr Mnshwrh. Klyt Altrbyh, Qsm Almnahj Wtrq Altdrys

14. Mhmd, Alzaky, Mna Mstfa (2013). Edrak Alzwjh Lhqwqha Wwajbatha (Fy Dw' Alktab Walsnh) W'laqth Bjwdh Hyatha. Rsalt Mnshwrh. Mjlt 'lwm Wfnwn- Drasat Wbhwth- Msr

15. Alnasr, Ebrahym Nasr (2008). Wthyqt Hqwq Almrah Wwajbatha Fy Aleslam. Alryad: Mrkz Bahthat Ldrasat Almrah.

16. Alrazy,Mhmd Bn Aby Bkr Bn 'bdalqadr (2009). Mkhtar Alshah. Dar Alhdyth: Alqahrh.

17. Alrwyly, Nwrh Mflh (2008). Al'waml Alm'thrh Bw'y Alshabh Als'wdyh Bhqwqha, Drash Asttla'yh 'la 'ynh Mn Talbat Jam't Almlk S'wd Fy Mdynh Alryad. Rsalt Majstyr Ghyr Mnshwrh. Klyt Aladab. Qsm Aldrasat Alajtma'yh.

18. Alsalh,Mhmd Ahmd (2002). Hqwq Alensan Fy Alqran Walsnh Wttbyqatha Fy Almmlkh Al'rbyh Als'wdyh. Hqwq Altb'h Alawla.

19. Sanw, Qtb Mstfa (1999). M'jm Mstlhat Aswl Alfqh 'rby Anklyzy. Dar Alfkr: Dmshq.

20. T'ymh,Rshdy.(2008). Thlyl Almhtwa Fy Al'lwm Alensanyh Mfhwmh .Assh. Astkhdamath. Dar Alfkr Al'rby: Alqahrh.

21. Altrky, Mna Hsyn Trky (2010). Mda Tdmyn Wthyqh Mnhj Mwad Al'lwm Alshr'yh Fy Alt'lym Alasasy Lmbad' Hqwq Alensan. Rsalt Majstyr Ghyr Mnshwrh Klyt Altrbyh, Qsm Almnahj Wtrq Altdrys, Jam't Almlk S'wd, Alryad.

22. Wzart Altrbyh Walt'lym (2009). Dlyl Almdrsh Alt'lym Althanwy (Nzam Almqrrat). Alasdar Althany.

23. Wzart Altrbyh Walt'lym. (2010). Dlyl Alt'lym Althanwy (Nzam Almqrat). Alasdar Alrab'.

24. Wzart Alm'arf (1970). Syash Alt'lym Fy Almmlkh Al'rbyh Als'wdyh. 